\title{
Fuzzy Tools in Recommender Systems: A Survey
}

\author{
Raciel Yera ${ }^{1}$, Luis Martínez ${ }^{2}$ \\ ${ }^{1}$ University of Ciego de Ávila, \\ Carretera a Morón Km. 9 1/2, Ciego de Ávila, Cuba \\ yeratoledo@gmail.com \\ ${ }^{2}$ Computer Science Department, University of Jaén, \\ Campus Las Lagunillas, 23071, Jaén, Spain \\ martin@ujaen.es
}

Received 18 November 2016

Accepted 25 February 2017

\begin{abstract}
Recommender systems are currently successful solutions for facilitating access for online users to the information that fits their preferences and needs in overloaded search spaces. In the last years several methodologies have been developed to improve their performance. This paper is focused on developing a review on the use of fuzzy tools in recommender systems, for detecting the more common research topics and also the research gaps, in order to suggest future research lines for boosting the current developments in fuzzy-based recommender systems. Specifically, it is developed an analysis of the papers focused at such aim, indexed in Thomson Reuters Web of Science database, in terms of they key features, evaluation strategies, datasets employed, and application areas.
\end{abstract}

Keywords: recommender systems, user preferences, fuzzy logic, survey

\section{Introduction}

One of the most used paradigms for implementing personalization processes to provide users with the information resources that best fit their preferences and needs in an overloaded digital world are recommender systems. Even though, they were initially conceived to cover e-commerce domains [106, 113], today they are successfully expanded to diverse scenarios such as e-learning [147], tourism [95], libraries [146], e-government [77], financial investment [89], and other application areas [76].

According to the available information used to generate recommendations, recommender systems can be classified into different recommendation paradigms. Initially, demographic ones were the most important approaches because such information was available, but recently the two main recom- mendation paradigms are the collaborative filteringbased recommendation [94] and the content-based recommendation [34].

- Collaborative filtering systems can generate recommendations only using users' ratings and without the necessity of additional information. In its most basic approach [37, 106], collaborative filtering focuses on suggesting to the target user the items already preferred by other users with similar preference patterns.

- Content-based recommendation is focused on the use of additional information beyond users' ratings (such as items' attributes) to characterize items, and therefore suggest the items with similar features to those ones that the user preferred in the past. 
Beyond previous paradigms, several authors have referred to other paradigms such as social, knowledge-based or hybrid filtering [21], depending on the technique and information used for the recommendation generation.

A brief analysis of working principles of such paradigms evidences that the users' preferences play a main role in the recommendation generation process. Therefore, since 90s there have been developed a plethora of researches managing the user's preferences and also the additional users' and items' information, to obtain accurate recommendations $[21,41]$. Such researches have been successfully supported by foundations taken from related research areas such as user modelling, information retrieval, computational intelligence, or machine learning; and in several cases, their contribution to recommender systems has been built from the scratch.

Our interest is focused on soft computing techniques, mainly fuzzy-based, used in recommender systems [152]. Recent reviews on recommender systems and personalization [21, 41], show relevant approaches for managing uncertainty in recommender systems (see Fig.1) such as bayesian approaches [33], markov models [111], fuzzy approaches [152], genetic algorithms [47], or neural networks [137].

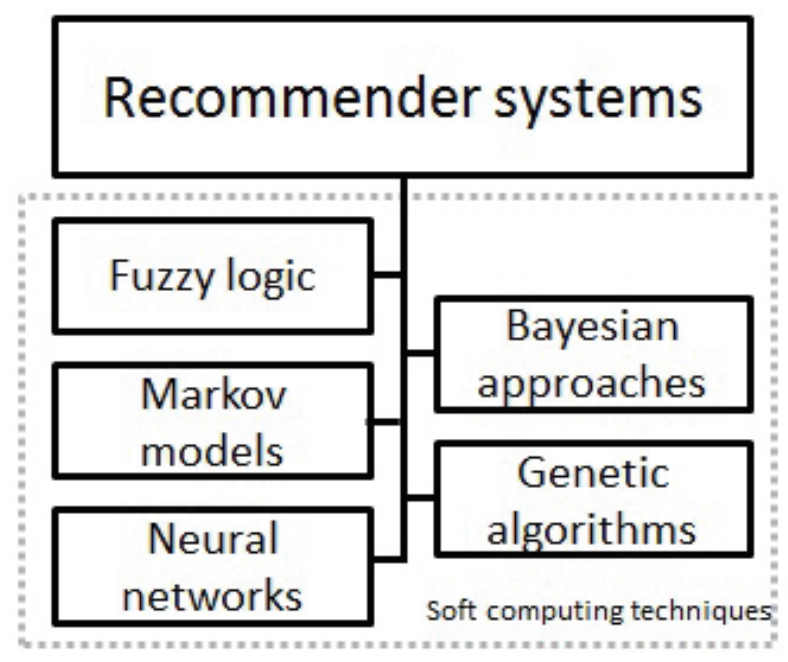

Fig. 1. Soft computing approaches in recommender systems development

In order to evaluate the relevance of such techniques in recommender systems, a search was developed in Thomson Reuters Web of Science (Core Collection) at October 2016. It was focused on finding relevant research combining such techniques for managing uncertainty, with traditional paradigms in recommender systems such as collaborative filtering-based, content-based, or demographic-based. The results obtained are shown in Fig. 5 and they suggest that it is worthy to develop a depth study focused on evaluating the current state-of-art on the use of fuzzy logic tools for improving the performance of recommender systems. Therefore, this paper is devoted to accomplish this aim.

Consequently, it is necessary to mention that even there have been developed several survey papers focused on recommender systems both regarding a wide point of view (Adomavicius and Tuzhilin [3], Konstan and Riedl [65], Bobadilla et al. [21]), and also focused on specific areas (Campos et al. [23], Klašnja-Milićević et al. [63], Abbas et al. [1], Martínez et al. [83]), according to our best knowledge (October 2016), the current paper is the first effort focused on concentrating all the research works focused on recommender systems supported by fuzzy tools.

The paper is structured as follows. Section 2 presents a brief background on recommender systems and fuzzy tools, and includes details related to content-based and collaborative filtering recommendation. Section 3 explains the survey methodology used for obtaining the research works to be considered. The main part of the contribution is developed in Section 4, by analysing the developments on fuzzy tools in recommender systems, grouped by the core approach they are based, according to the typical techniques used for building recommender systems. Section 5 pointed out future research directions for providing continuity to the current developments. Section 6 concludes the paper.

\section{Background}

This section is focused on presenting the necessary background for the current survey. First, a brief background on recommender systems is presented by focusing on the most widely-developed 


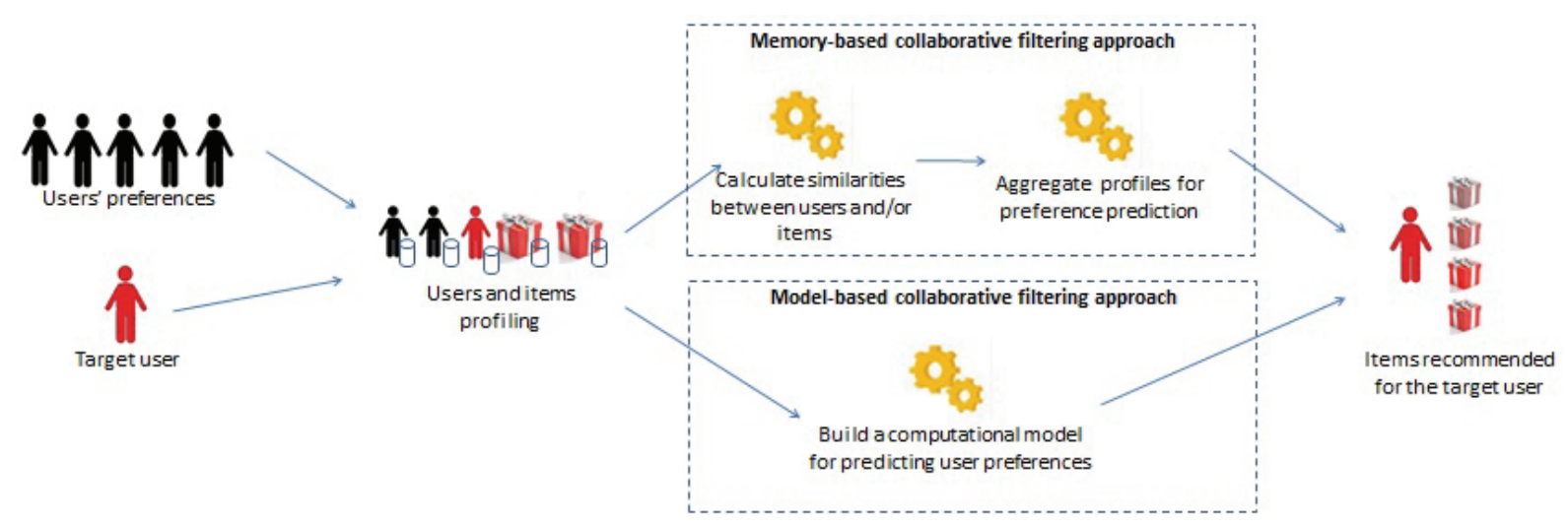

Fig. 2. Collaborative filtering-based recommendation

paradigms, specifically demographic, collaborative, content-based, and hybrid filtering. Afterwards, it is performed a quick reference to fuzzy logic concepts which are used across most of papers included in this survey.

\subsection{Recommender systems}

A recommender system is considered as "any system that produces individualized recommendations as output or has the effect of guiding the user in a personalized way to interesting or useful objects in a large space of possible options" [22]. Specifically, Gunawardana and Shani [44] have pointed out that the two more common tasks related to recommender systems are the prediction of user opinion (e.g., rating) over a set of items, the prediction task, and the recommendation of a set of good (interesting, useful) items to the user, the recommendation task. With such aims in mind, several recommendation approaches have been developed; and depending on their working principles, they have been classified into several categories according to the kind of information managed. One of the most popular classification has been pointed out by Bobadilla et al. [21], which groups them into a) demographic filtering, b) collaborative filtering, c) content-based filtering and d) hybrid filtering. The next subsections present a brief reference to these categories.

- Demographic filtering Early recommendation approaches were supported by demographic filtering, which is focused on managing user's at- tributes for the identification of his/her preferences and the use of such information for the recommendation generation [97]. It is supported by the principle that people with common personal attributes such as sex, age, country, and so on, may have also common preferences. Although this approach could seem simplistic at the first view regarding the current development of personalization technologies, recent works have shown its effectiveness in several recommendation scenarios [156, 157].

\section{- Collaborative filtering recommender systems}

The most popular paradigm for developing recommendation approaches is currently collaborative filtering, which is focused on performing the typical tasks of recommender systems using only users' rating values [3]. Usually, they generate the recommendations for the current user, by exploring the preferences of other related users regarding their degree of similarity. Such an exploration is typically based on their rating patterns. In contrast to content-based recommendation, this approach does not depend on items attributes; therefore it could be used in any recommendation scenario having enough preference values (Fig. 2). Collaborative filtering systems are typically classified into memory-based or model-based approaches [3]. A comprehensive analysis of such approaches can be found in related review papers such as Su and Khoshgoftaar [120], Ekstrand et al. [37], Bobadilla et al. [21] and Ning et al. [94]. 


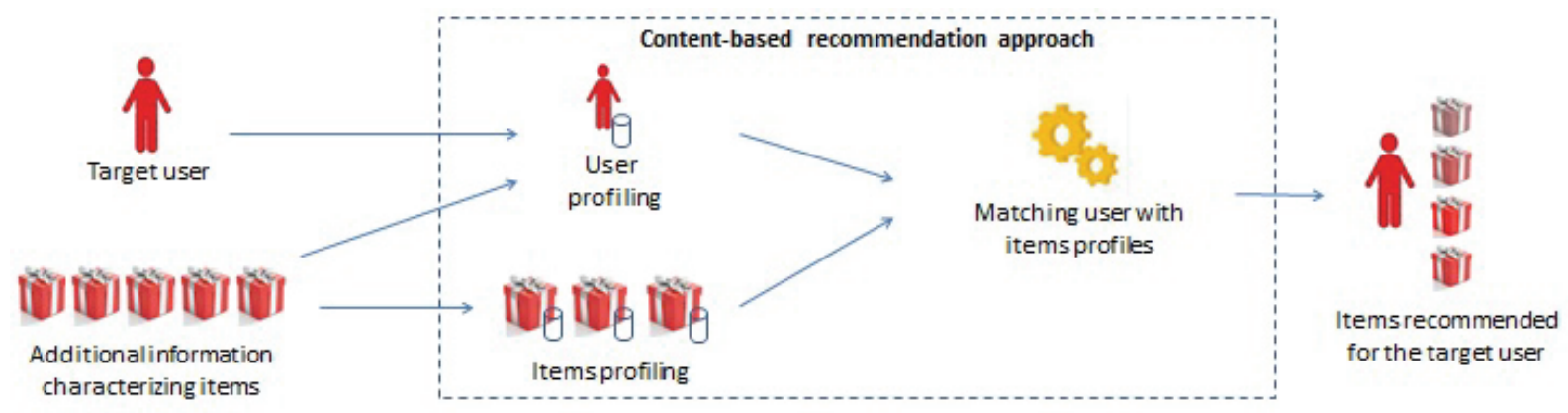

Fig. 3. Content-based recommendations

\section{- Content-based recommender systems}

In the last few years, the incremental growing of several platform managing high volumes of information related with user profiles, has increased the relevance of content-based recommendation. Content-based recommender systems take as reference the item's descriptions and a profile with the interests of the active user, for suggesting items similar to those the active user already liked in the past [75]. Basically, they focus on performing a comparison between the user profile and the candidate items, to determine which items will be recommended. Items profiles are usually represented through a set of attributes that can include weights to represent the importance of each one of them [3]. Taking into account the preference degrees of users about items and such attributes values, there are usually proposed computational approaches to learn the user profiles in terms of the same attributes. Afterwards, it could be used several matching approaches between users and items for the recommendations generation (Fig. 3 ). Two relevant surveys on content-based recommendation have been presented by Lops et al. [75] and de Gemmis et al. [34].

\section{- Hybrid recommender systems}

Several researches have proposed hybridizations of some of the previous approaches for simultaneously overcoming their limitations. Some popular hybridization approaches are the combination of collaborative and demographic filtering [132], or collaborative and content-based filtering [12]. Specifically, a still-updated survey developed by Burke [22], has pointed out six differ- ent techniques for hybridization of recommender systems, which are weighted, mixed, switching, feature combination, feature augmentation, and meta-level.

Because of the diversity of information sources that are emerging nowadays, an important amount of the recommender systems developed in the last few years could be classified as hybrid systems.

\subsection{Fuzzy logic tools}

Fuzzy logic is focused on modelling some real world concepts which cannot be represented in a precise way. Specifically, the definition of a fuzzy set [151] over a universe of discourse, extends the notion of a set through the introduction of the degree of membership of the elements. It establishes a correspondence between the elements of the universe of discourse $X$ into the interval $[0,1]$, given by a membership function:

$$
\mu_{\widetilde{A}}: X \rightarrow[0,1]
$$

Based on this membership function, a fuzzy set $\widetilde{A}$ defined over the domain $X$ is represented by the set of pairs of the element $x$ and its membership:

$$
\widetilde{A}=\left\{\left(x, \mu_{\widetilde{A}}(x)\right) / x \in X, \mu_{\widetilde{A}}(x) \in[0,1]\right\}
$$

Let $\widetilde{A}$ be a fuzzy set. The $\alpha$-cut of $\widetilde{A}$ is defined as

$$
\widetilde{A}_{\alpha}=\left\{x \in \mathbb{R} \mid \mu_{\widetilde{A}}(x) \geqslant \alpha\right\} .
$$

Also the notions of intersection and union over tra- 
ditional sets are extended to be defined for fuzzy sets [151, 158], see Eqs. 3) and 4) respectively:

$$
\begin{array}{ll}
\mu_{\widetilde{A} \cap \widetilde{B}}(x)=i\left[\mu_{\widetilde{A}}(x), \mu_{\widetilde{B}}(x)\right], & x \in X \\
\mu_{\widetilde{A} \cup \widetilde{B}}(x)=u\left[\mu_{\widetilde{A}}(x), \mu_{\widetilde{B}}(x)\right], & x \in X,
\end{array}
$$

being $i$ and $u$ fuzzy binary operations, usually referred in the literature as t-norms and t-conorms, respectively.

The fuzzy linguistic approach $[46,108]$ is useful for modelling uncertain and vague preferences in recommender systems by using the concept of linguistic variable [150]. Its use implies the selection of appropriate linguistic descriptors for the term set, and their syntax and semantics. The semantics associated to the syntax are represented by fuzzy membership functions (see Fig. 12). Different linguistic computational models have been introduced, being the Computing with words methodology the most relevant taking into account the use of fuzzy linguistic modeling $[81,82,107,110]$.

The following sections present how these tools have been extensively used for managing the uncertainty associated to recommender systems.

\section{Survey methodology and initial results}

Recommender systems have been involved in a high volume of research works in recent years. To obtain a relevant and representative sample of such works, we searched on a well-recognized database of high-quality scientific literature, that is Thomson Reuters Web of Science (WoS). Specifically, it was executed a query focused on retrieving the mainstream research in recommender systems (the query was ("recommender systems" or recommendation) and (collaborative or content-based or demographic)), which retrieved, at October 2016, exactly 1432 records. Figure 4 presents the temporal distribution of such records, suggesting an important increase of results associated to the last four years, and therefore proving the interest of the research community on recommender systems nowadays.

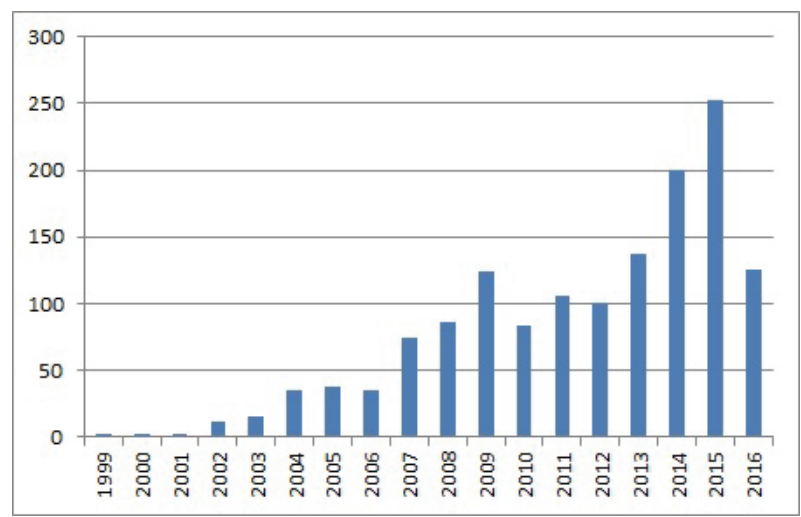

Fig. 4. Temporal distribution of papers on recommender systems.

As it was pointed out in the section 1, our interest is focused on recommender systems supported by soft computing approaches. Therefore, we refine the search results presented in Figure 4 by performing new queries (("recommender systems" and approach) or (recommendation and approach)) and (collaborative or content-based or demographic), being approach respectively replaced by: 1) "fuzzy", 2) "bayesian", 3) "markov", 4) "genetic algorithm", and 5) "neural network".

Figure 5 shows the amount of results obtained for each query, being relevant the amount of papers that consider the use of fuzzy tools (152 results), over the remaining categories. This list of papers suggests the necessity of evaluating the current state-ofart on the use of fuzzy logic tools for improving the performance of recommender systems.

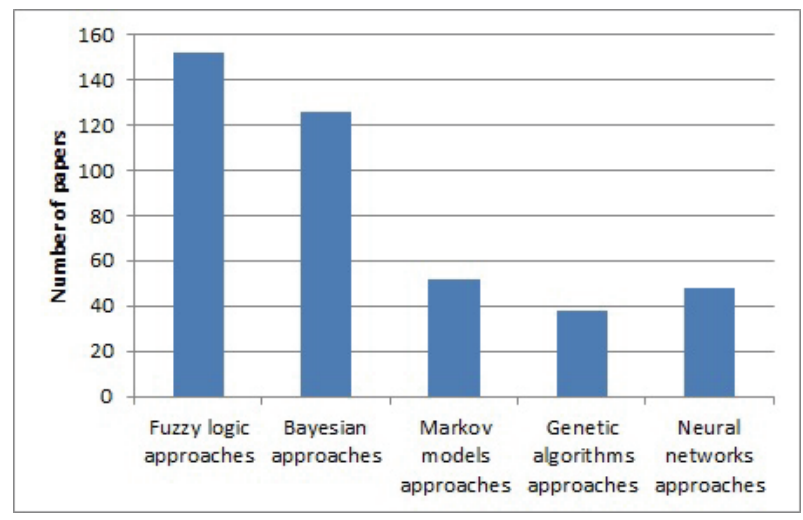

Fig. 5. Search results in Thomson Reuters WoS, for recommender systems, and different soft computing techniques. 
Such a list was considered as the preliminary list of papers to be included in our survey, because in it still remains some papers that are not focused on recommender systems. Hence, we developed a manual procedure (Figure 6) to keep in the list those papers related to the recommendation system research field, which also incorporate fuzzy logic approaches in their proposals. In addition, it was also considered the fact that there could be several papers presenting the same research results, and therefore were excluded those papers that contain preliminary results extended later by other research papers already included in the list.

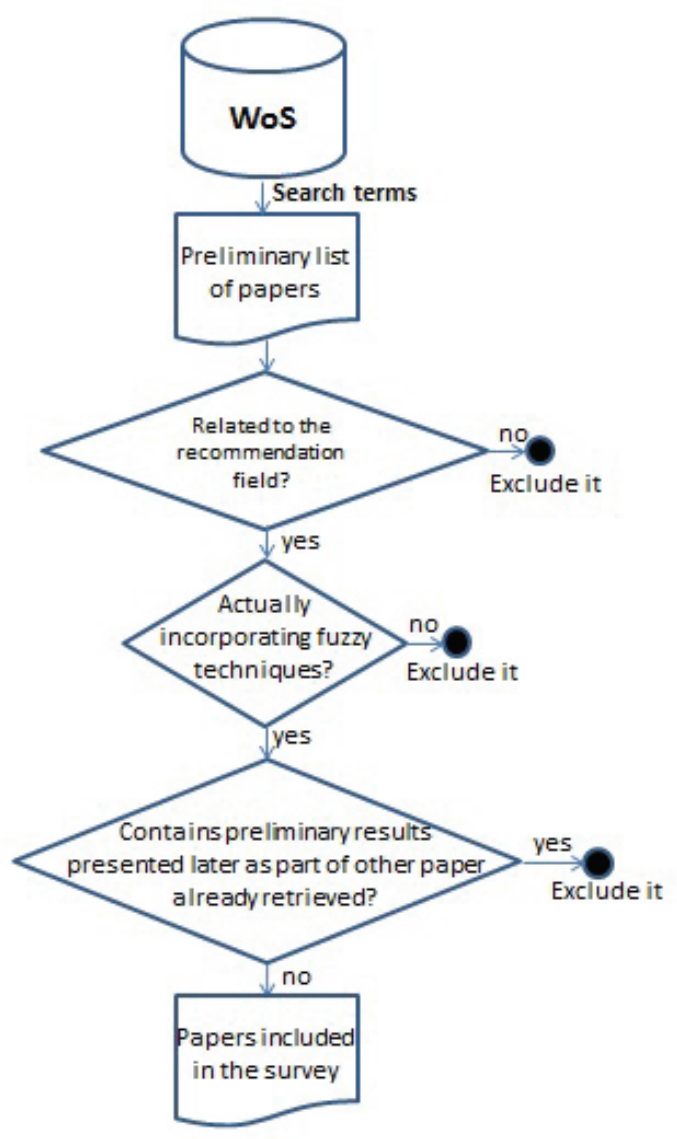

Fig. 6. Survey methodology.

This manual procedure obtains as final result a list of 108 papers, that was the definitive list to be analysed in the current paper.

In order to obtain an initial snapshot of this final list of papers, it was built a tag cloud (Figure 7 using the online tool http://tagcrowd.com/) consid- ering the keywords associated to each paper. When papers did not contain associated keywords, their titles were used as input for the tag cloud.

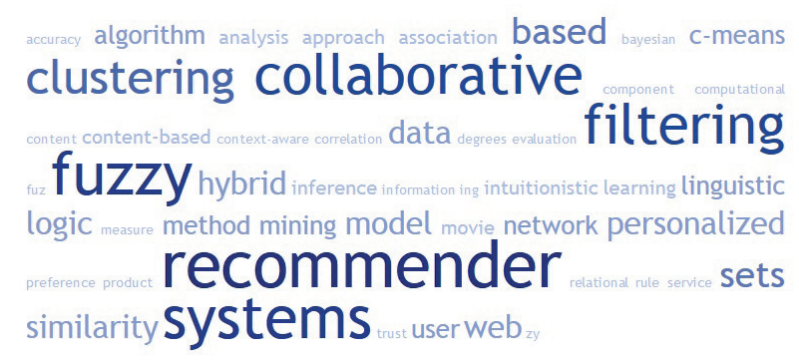

Fig. 7. Tag cloud associated to the keywords of the list of papers to be analysed.

In such a tag cloud, as it was expected, the more important terms are related to collaborative filtering, recommender systems and fuzzy sets. Although content-based recommendation does not seem to play a relevant role here, next section will show that it is associated to an important segment of proposals. This cloud also shows other relevant terms such as clustering, similarity, or linguistic.

Figure 8 presents a temporal distribution of the papers, by differentiating journal and conference papers. It suggests that in the last years the amount of papers focused on fuzzy approaches has been increased.

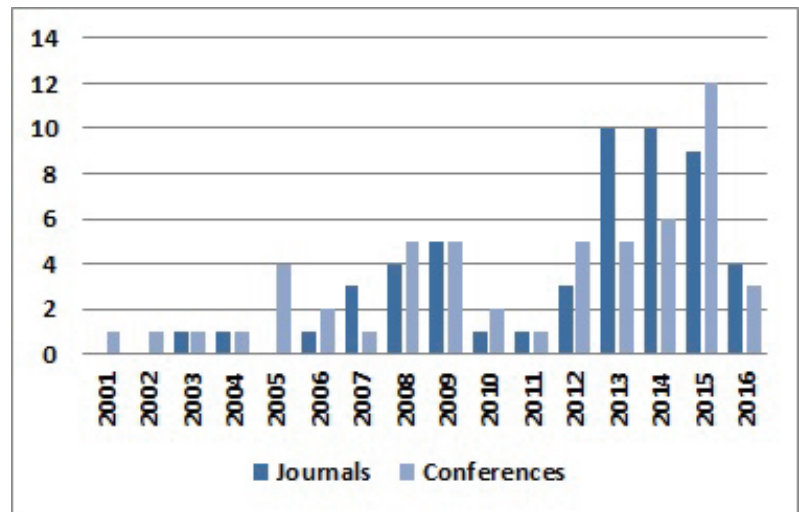

Fig. 8. Temporal distribution of the list of papers.

In addition, the distribution of main journals and conferences associated to the list of papers is shown in Figure 9. The majority of the papers were concentrated in popular journals in the field of information/intelligent systems and fuzzy logic, such as 
Expert Systems with Application, Information Sciences, International Journal of Intelligent Systems, Applied Soft Computing, or Fuzzy Sets and Systems. Beyond such a figure, there are 17 journals contributing to the retrieved list with just one paper.

Unlike journal papers, the origin of the conference papers is more heterogeneous. Here, the most represented conferences were the IEEE International Conference on Fuzzy Systems (FUZZIEEE) (8 papers), IEEE International Conference on Systems, Man, and Cybernetics (IEEE SMC) (3 papers), and International Conference on Intelligent Systems and Knowledge Engineering (ISKE) (3 papers).

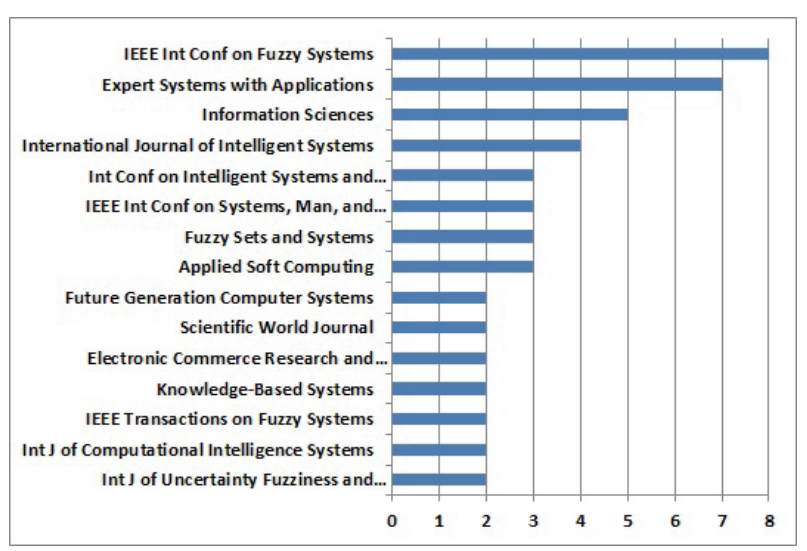

Fig. 9. Main journals and conferences distribution across the papers.

Following section introduces a comprehensive presentation about the proposals of this final list of contributions.

\section{Review on fuzzy tools in recommender systems}

Initially, the final list of papers is grouped by considering the typical classification of recommender systems, already presented in Section 2.1. Therefore, this section considers three big groups of fuzzy recommendation approaches: 1) the approaches focused on content-based recommendation (Section $4.1), 2$ ) those ones focused on memory-based collaborative filtering (Section 4.2), and 3) the approaches focused on model-based collaborative filtering (Section 4.3). Regarding demographic sys- tems, it could be pointed out that currently demographic recommenders are almost always integrated with other recommendation approaches (e.g. content-based or collaborative filtering recommendation). Therefore, it was taken as reference for including systems that use demographic features in one of the three mentioned big groups of fuzzy recommendation approaches.

It is remarkable that the hybrid nature of most of the reviewed researches implies that some of them could simultaneously belong to more than one group. In such cases the corresponding papers were added to the group related to their most important contribution according to our criteria.

The analysis of each group will conclude with a discussion subsection presenting the strengths and weaknesses in the use of fuzzy tools, associated to the corresponding group of research works.

\subsection{Content-based recommendation approaches with fuzzy tools}

This section is focused on presenting the contributions related to the use of fuzzy tools in contentbased recommendation. First, Section 4.1.1 presents an analysis of the proposals identified in Section 3 focused on content-based recommendation, being complemented with Table 1 which presents an exhaustive survey of such works. Finally, Section 4.1.2 discusses the global strengths and weaknesses of the analysed works.

\subsubsection{Proposals}

The contributions related to the application of fuzzy tools to content-based recommender systems (CBRS) are reviewed here. The two main phases of a CBRS scheme (Fig. 3) are the profiling (user/item) and the matching process to suggest appropriate items to users. Fuzzy tools have been applied to both of them (see Fig. 10). 


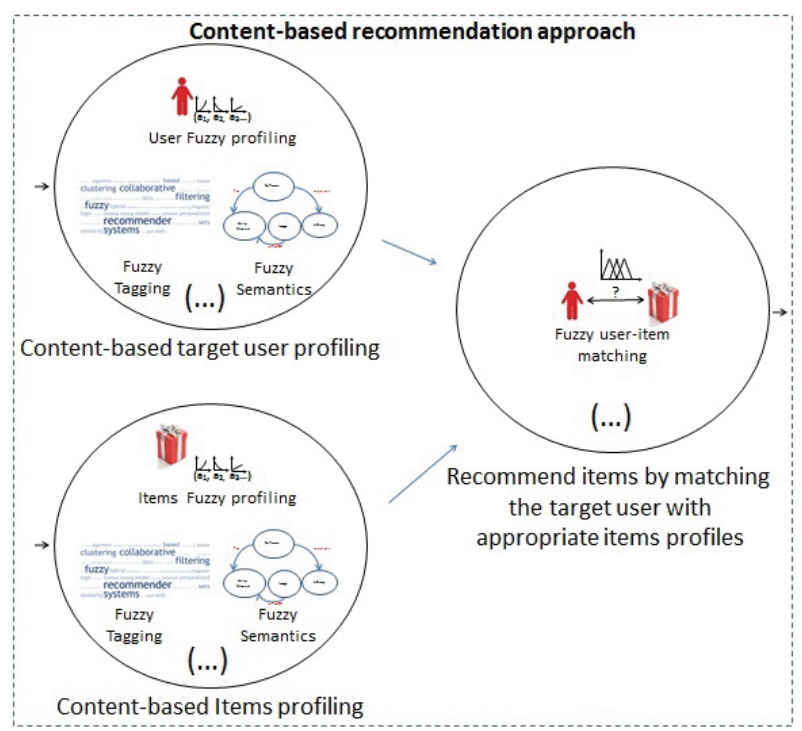

Fig. 10. Content-based recommendation using fuzzy tools

A pioneer work on the use of fuzzy logic in content-based recommendation was developed by Yager [145], that presented approaches for constructing recommender systems based on reclusive methods, closely connected to content-based recommendation. Such approaches deal with object representation, user preferences modelling, user profiling, extensionally expressed preferences, and the use of domain expert prototypes. Additionally, Karacapilidis and Hatzieleftheriou [60] also presented an early work focused on a similar direction.

More recently, Zenebe and Norcio [152] proposed a representation method for items' features and user feedback using fuzzy sets, and a contentbased recommendation algorithm based on various fuzzy set theoretic similarity measures (the fuzzy set extensions of the Jaccard index, cosine, proximity or correlation similarity measures), and aggregation methods for computing recommendation confidence scores (the maximum-minimum or Weightedsum fuzzy set theoretic aggregation methods).

In [152], $\mu_{x_{i}}\left(I_{k}\right)$ is the degree of membership of movie $I_{k}(k=1, \ldots, M)$ to genre $x_{i}(i=1, \ldots, N)$, and it is used for proposing the application of typical similarity measures for comparing items, such as fuzzy set theoretic (Eq. 5) and cosine similarities (Eq. 6).

$$
\begin{array}{r}
S_{1}\left(I_{k}, I_{j}\right)=\frac{\sum_{i} \min \left(\mu_{x_{i}}\left(I_{k}\right), \mu_{x_{i}}\left(I_{j}\right)\right)}{\sum_{i} \max \left(\mu_{x_{i}}\left(I_{k}\right), \mu_{x_{i}}\left(I_{j}\right)\right)} \\
S_{1}\left(I_{k}, I_{j}\right)=\frac{\sum_{i} \mu_{x_{i}}\left(I_{k}\right) * \mu_{x_{i}}\left(I_{j}\right)}{\sqrt{\sum_{i}\left(\mu_{x_{i}}\left(I_{k}\right)^{2}\right)} \sqrt{\sum_{i}\left(\mu_{x_{i}}\left(I_{j}\right)^{2}\right)}}
\end{array}
$$

In addition, they use a half triangular fuzzy number to represent the degree of positive experiences a user has in relation with an item. This function, being rating $r \in[$ Min,Max $]$ on $I_{i}$, Min and Max the minimum and maximum rating value, and $A$ a fuzzy set representing degree of interest, is defined as:

$$
\mu_{A}\left(I_{i}\right)=(r-\text { Min }) /(\text { Max }- \text { Min })
$$

Consequently, a set of items $\mathrm{E}$ liked by a user, is defined as $E=I_{i}: \mu_{A}\left(I_{i}\right)>0.5$.

Finally, they suggest several approaches to aggregate preferences for computing the recommendation confidence score, such as the weighted sum, maximum and minimum. Eq. (8) presents the weighted sum strategy, where $E$ is the set of preferred items and $\mu_{E}\left(I_{k}\right)$ is the membership of the item $k$ to $E . S\left(I_{j}, I_{k}\right)$ is the similarity between $I_{j}$ and $I_{k}$ :

$$
R_{1}\left(I_{j}\right)=\sum_{k} \mu_{E}\left(I_{k}\right) S\left(I_{k}, I_{j}\right)
$$

In this way, several authors have developed similar researches, such as flexible models of user preference learning from rating values in CBRS, supported by fuzzy sets [50], being some approaches empowered by bioinspired algorithms such as particle swarm optimization [136], to learn user weights on various features. Here it is worthy to note the development of tag-based user profiling methods for improving recommendations [9], where user profiles are built through a folksonomy-based approach that evaluates items according to the membership degrees to various attribute values, which are then used to compute the fuzzy user profile. Additionally, in the last few years further works on the use of fuzzy tools for modelling specific items' features in CBRS have been developed [2, 5, 14, 69, 96, 99, 104, 126]. 
Recently there have also been an increasing use of more sophisticated fuzzy linguistic approaches for modelling content in recommender systems, such as the 2-tuple fuzzy linguistic approach [46]. In this direction, some early works enriched the typical content-based recommendation scheme by incorporating fuzzy linguistic variables for modelling the preferences [79], subsequently considering more flexible frameworks for capturing the uncertainty of such user's preferences [80], even considering incomplete information [84]. Additionally, such sophisticated fuzzy linguistic approaches have also supported the construction of systems for recommending diverse items such as research resources [100, 115], or furniture products [42].

Beyond the direct content modelling task, there have been identified some works focused on taking benefits of fuzzy approaches for mitigating the effect of the cold start and data sparsity issues. In this way, Rodríguez et al. [109] use a fuzzy linguistic approach and incomplete preference relations to build a recommender system, where the user initially has to select a small set of favourite items, and such items are used for completing a preference relation. Wu and Hwang [140] also use users' preferences over genres to build a user-movie matrix which is transformed through fuzzy max-min operations to alleviate its sparsity.

It was also identified that several proposals such as $[36,53,77,88]$ have focused on combining fuzzy logic with semantic web technologies, in order to improve recommendations.

Christakou et al. [31] proposed the use of fuzzy aggregation operators, specifically Ordered Weighted Averaging operators (OWA), as a way for constructing hybrid recommender systems by combining the output of two recommendation components: a neural network-based content filtering, and a collaborative filtering component.

Finally, Mao et al. [78] proposed a fuzzy content matching-based recommendation approach to assist e-Commerce customers to choose their truly interested items. In that paper, users' ratings and preferences are represented using fuzzy numbers to remain uncertainties. Additionally, here treestructured content information is transformed into a set of descriptors, and users' preferences on these descriptors are derived from fuzzy ratings by using fuzzy number operations.

Table 1 presents a further detailed exhaustive analysis of the content-based recommendation approaches supported by fuzzy tools, regarding the key features, the performed evaluation approach, the datasets used, and the application area, if proceeds.

\subsubsection{Discussion}

The analysis of Table 1 leads to the identification of the following strengths and weaknesses in this group of works, which could be considered for the development of future research.

\section{Strengths:}

- The presence of several works focused on managing items' attributes with fuzzy techniques, strengthening the development of uncertaintyaware content-based recommender systems.

- The use of mainstream approaches for linguistic modelling, such as the 2-tuple model, allowing the exploitation of their advantages in the recommender systems scenarios.

\section{Weaknesses:}

- The contribution of some research works is limited because they claim for contributions related to the link between content-based recommendation and fuzzy logic, already introduced in previous papers also analysed.

- Several researches (50\% of the analysed works) do not incorporate experimental evaluation, notably limiting the novelty and the scope of the fuzzy logic-supported approaches.

- Most of proposals are focused on the fuzzy modelling of items' attributes, instead of the users' preferences, which are the main source of uncertainty in recommender systems.

- Some interesting research branches for uncertainty management, such as the use of OWA operators, have not received the sufficient attention in the last few years.

- Few works explore possible bridges between semantics and fuzzy logic. 
Table 1. Content-based fuzzy recommendation

\begin{tabular}{|c|c|c|c|c|}
\hline Papers & Key feature & Evaluation & Datasets & Application Area \\
\hline Yager [145] & $\begin{array}{l}\text { Constructs recommender systems through fuzzy reclusive (content- } \\
\text { based) methods }\end{array}$ & No & No & No \\
\hline $\begin{array}{l}\text { Karacapilidis and } \\
\text { Hatzieleftheriou } \\
{[60]}\end{array}$ & Incorporate a fuzzy similarity measure [135] & $\begin{array}{l}\text { MAE, Robust- } \\
\text { ness }\end{array}$ & $\begin{array}{l}\text { Movielens, PTV } \\
\text { database }\end{array}$ & Cities to visit \\
\hline $\begin{array}{l}\text { Christakou et al. } \\
\text { [31] }\end{array}$ & $\begin{array}{l}\text { Use OWA operators as aggregation scheme for building hybrid recom- } \\
\text { mender systems }\end{array}$ & Prec/Recall & Movielens & No \\
\hline $\begin{array}{l}\text { Martínez et al. } \\
\text { [79] }\end{array}$ & $\begin{array}{l}\text { Introduce a multigranular linguistic context for expressing the user pref- } \\
\text { erences }\end{array}$ & Scenario of use & No & No \\
\hline $\begin{array}{l}\text { Martínez et al. } \\
{[80]}\end{array}$ & $\begin{array}{l}\text { Allow users to express their necessities in scales closer to their own } \\
\text { knowledge, and different from the items' scale }\end{array}$ & Scenario of use & No & No \\
\hline $\begin{array}{l}\text { Martínez et al. } \\
{[84]}\end{array}$ & $\begin{array}{l}\text { Overcome the problem of lack of information in recommendation gen- } \\
\text { eration by completing incomplete linguistic preference relations }\end{array}$ & Scenario of use & No & No \\
\hline Porcel et al. [100] & $\begin{array}{l}\text { Recommendation in a technology transfer office, based on fuzzy lin- } \\
\text { guistic modelling ( } 2 \text {-tuple) }\end{array}$ & No & No & $\begin{array}{l}\text { Research } \\
\text { sources }\end{array}$ \\
\hline Horváth [50] & $\begin{array}{l}\text { Alternative modelling of user preference learning tasks in content-based } \\
\text { recommendation }\end{array}$ & No & No & No \\
\hline $\begin{array}{l}\text { Morales-del } \\
\text { Castillo et al. } \\
{[88]}\end{array}$ & $\begin{array}{l}\text { Combine semantic web technologies, fuzzy linguistic modelling tech- } \\
\text { niques, and content-based and collaborative approaches }\end{array}$ & Prec/Recall/F1 & $\begin{array}{l}\text { Dataset extracted } \\
\text { from an open ac- } \\
\text { cess repository }\end{array}$ & Digital libraries \\
\hline $\begin{array}{l}\text { Zenebe and Nor- } \\
\text { cio [152] }\end{array}$ & $\begin{array}{l}\text { Content-based recommendation using various fuzzy set theoretic simi- } \\
\text { larity measures and fuzzy aggregation methods }\end{array}$ & Prec/Recall/F1 & Movielens & No \\
\hline $\begin{array}{l}\text { Recio-García } \\
\text { et al. [104] }\end{array}$ & $\begin{array}{l}\text { Bridge recommendation and case-based reasoning. Consider group rec- } \\
\text { ommendation task }\end{array}$ & Scenario of use & Non public & Music \\
\hline $\begin{array}{l}\text { Rodríguez et al. } \\
{[109]}\end{array}$ & $\begin{array}{l}\text { Management of incomplete preferences relations. Supported by the } 2 \text { - } \\
\text { tuple fuzzy linguistic model }\end{array}$ & Scenario of use & No & Restaurants \\
\hline $\begin{array}{l}\text { Serrano-Guerrero } \\
\text { et al. [115] }\end{array}$ & $\begin{array}{l}\text { Communicating researchers interested in common research lines, based } \\
\text { on fuzzy linguistic modelling ( } 2 \text {-tuple) }\end{array}$ & $\begin{array}{l}\text { Scenario of use, } \\
\text { Prec/Recall/F1 }\end{array}$ & No & $\begin{array}{l}\text { Research re- } \\
\text { sources }\end{array}$ \\
\hline Pinto et al. [99] & Recommendation in online stores regarding marketing concepts & Prec/Recall/F1 & Non public & Online stores \\
\hline Lee $[69]$ & $\begin{array}{l}\text { Recommends items or web pages suitable to the users' understanding } \\
\text { levels }\end{array}$ & Prec/Recall/F1 & $\begin{array}{l}\text { Data generated } \\
\text { by a simulator }\end{array}$ & Web pages \\
\hline $\begin{array}{l}\text { Bedi and Agar- } \\
\text { wal [14] }\end{array}$ & $\begin{array}{l}\text { Focused on recommending relevant items at the right context, deter- } \\
\text { mined using fuzzy inference }\end{array}$ & No & No & Restaurants \\
\hline $\begin{array}{l}\text { Djaghloul et al. } \\
{[36]}\end{array}$ & $\begin{array}{l}\text { Formalize the balance between interest-related content matching and } \\
\text { situation matching (context) }\end{array}$ & $\begin{array}{l}\text { Cross validation } \\
\text { regarding RMSE }\end{array}$ & Non public & $\begin{array}{l}\text { E-commerce } \\
\text { dataset }\end{array}$ \\
\hline $\begin{array}{l}\text { Wu and Hwang } \\
{[140]}\end{array}$ & Content-based movie preference modelling supported by movie genre & $\begin{array}{l}\text { Precision and } \\
\text { time cost }\end{array}$ & Movielens & Movie \\
\hline Lu et al. [77] & $\begin{array}{l}\text { Combine item-based fuzzy semantic similarity and item-based fuzzy } \\
\text { collaborative filtering similarity }\end{array}$ & $\begin{array}{l}\text { MAE, Coverage, } \\
\text { Prec/Recall/F1 }\end{array}$ & $\begin{array}{l}\text { Movielens, a non } \\
\text { public dataset }\end{array}$ & $\begin{array}{l}\text { Business partner } \\
\text { recommendation }\end{array}$ \\
\hline $\begin{array}{l}\text { Gerogiannis et al. } \\
\text { [42] }\end{array}$ & $\begin{array}{l}\text { Helping buyers of high involvement products with the purchasing pro- } \\
\text { cess, supported by fuzzy information modeling (2-tuple) }\end{array}$ & No & No & $\begin{array}{l}\text { Furniture manu- } \\
\text { facturing }\end{array}$ \\
\hline $\begin{array}{l}\text { Pardines et al. } \\
{[96]}\end{array}$ & $\begin{array}{l}\text { System included in a mobile application that manages information re- } \\
\text { lated to an environmental educational program. }\end{array}$ & No & No & $\begin{array}{l}\text { Environmental } \\
\text { activities }\end{array}$ \\
\hline Adnan et al. [2] & A news recommendation scenario supported by fuzzy logic & No & No & News \\
\hline $\begin{array}{l}\text { Anand and } \\
\text { Mampilli [9] }\end{array}$ & Tag-based user profiling method for improving recommendations & $\begin{array}{l}\text { Precision and } \\
\text { Rank Accuracy }\end{array}$ & Movielens+HetRec & No \\
\hline $\begin{array}{l}\text { Wasid and Kant } \\
{[136]}\end{array}$ & $\begin{array}{l}\text { Use fuzzy sets for modelling user features, and particle swarm opti- } \\
\text { mization for weighting it. }\end{array}$ & $\begin{array}{l}\text { MAE and Cover- } \\
\text { age }\end{array}$ & Movielens & No \\
\hline $\begin{array}{l}\text { Al-Qaheri and } \\
\text { Banerjee [5] }\end{array}$ & Quantify optimal social innovation-based policy recommendations & No & No & $\begin{array}{l}\text { Policy recom- } \\
\text { mendations }\end{array}$ \\
\hline Huang et al. [53] & $\begin{array}{l}\text { Ontology-based recommendation model based on a fuzzy rough set- } \\
\text { based hybrid mechanism }\end{array}$ & No & No & No \\
\hline Mao et al. [78] & $\begin{array}{l}\text { Fuzzy content matching-based recommendation approach regarding } \\
\text { tree-structured content }\end{array}$ & Coverage, nDCG & Movielens, Yelp & No \\
\hline Tsai [126] & $\begin{array}{l}\text { Provides suggestions for business collaboration, representing informa- } \\
\text { tion through fuzzy vectors }\end{array}$ & AUC/F1 & Yelp & $\begin{array}{l}\text { Business collabo- } \\
\text { ration }\end{array}$ \\
\hline
\end{tabular}




\subsection{Memory-based collaborative filtering approaches with fuzzy tools}

This section is devoted to present the contributions focused on incorporating fuzzy approaches in memory-based collaborative filtering recommendation. First, Section 4.2.1 presents an analysis of the proposals identified in Section 3, focused on memory-based collaborative filtering recommendation. This analysis is complemented with Tables 24, which present an exhaustive survey of such works. Finally, Section 4.2.2 discusses the global strengths and weaknesses of the analysed works.

\subsubsection{Proposals}

In this recommendation paradigm, the similarity functions to compare users/items play a relevant role (see Fig. 2), together the approaches for aggregating the neighbours' preferences, to obtain the final recommendations. In this way, Fig. 11 presents a synthetic overview on how fuzzy approaches are used for developing these components. Specifically, this section is focused on presenting three groups of contributions: 1) Collaborative filtering using only rating values, 2) Demographic information and items attributes to improve the memory-based collaborative filtering recommendation, and 3) Trust values into the typical recommendation scenario.

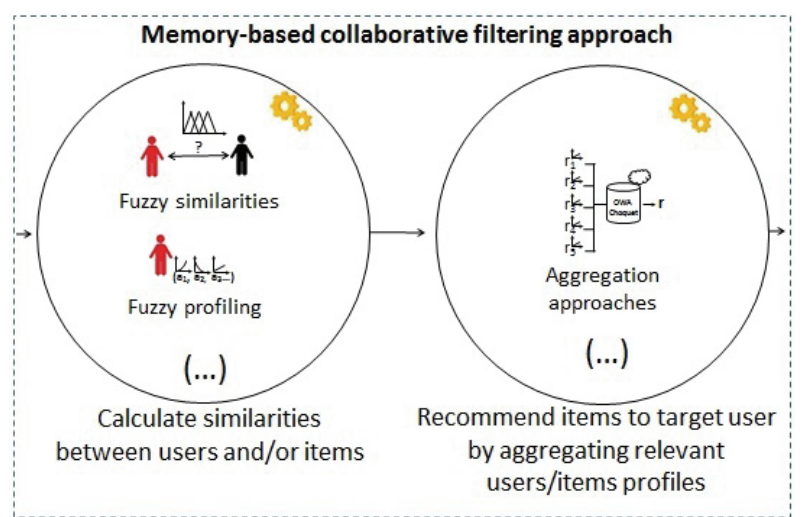

Fig. 11. Memory-based collaborative filtering recommendation using fuzzy tools

Collaborative filtering using only preferences. Table 2 presents an exhaustive analysis of the approaches that perform collaborative filtering just us- ing rating values. Below it is highlighted the most important contributions of such works.

Aguzzoli et al. [4] proposed a fuzzy logic-based approach for collaborative filtering, showing how many-valued logic is flexible enough to perform collaborative filtering, content-based, and hybrid recommender systems.

Beyond this first work, most of the research related to memory-based collaborative filtering has been focused on proposing new similarity measures between users or items (see Fig. 2), that extend typical measures (e.g. Pearson and cosine [3]) by using fuzzy concepts. Specifically, our survey methodology detected that Al-Shamri and Al-Ashwal [6], Castellano et al. [24], Cheng and Wang [30], Cornelis et al. [32], Reformat and Yager [105], Wang et al. [134], Zhang et al. [155] and Zhang et al. [154] are focused at such aim, only using preference values and without any additional information.

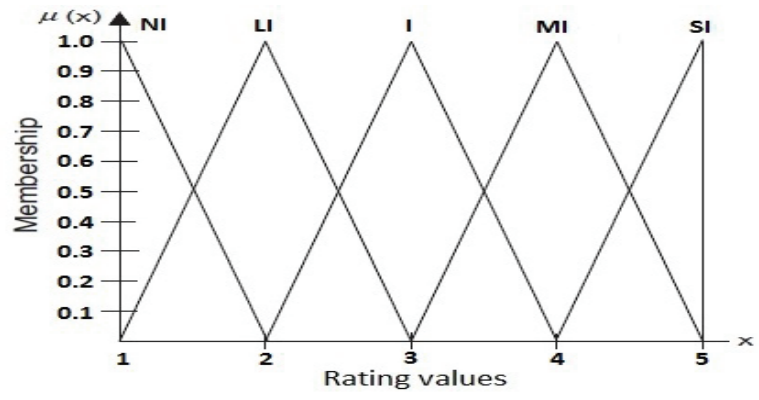

Fig. 12. Fuzzy sets and membership functions for a fuzzy collaborative filtering system.

As an example, Fig. 12 shows the fuzzy sets proposed by [155] for a fuzzy collaborative recommendation approach: \{Strongly Interested (SI), More Interested (MI), Interested (I), Less Interested (LI), Not Interested (NI)\}. Such research uses these linguistic terms to propose fuzzy extensions of Pearson correlation coefficient for performing user-user and item-item comparisons, and finally such similarities are combined for predicting unknown ratings. Equation (9) presents the fuzzy similarity function for comparing two items, where $S_{x, y}$ represents the set of users that rate both the items $x$ and $y ; r_{x, S_{\alpha}}$ and $r_{y, S_{\alpha}}$ represent the ratings of user $s$ on items $x$ and $y$ under $\alpha$-cut respectively; $r_{x, S_{\alpha}}^{-}$and $r_{x, S_{\alpha}}^{+}$are the leftend and the right-end of $\alpha$-cut respectively, and $r_{y_{\alpha}}$ 
Table 2. Memory-based collaborative filtering using only preferences

\begin{tabular}{|c|c|c|c|c|}
\hline Papers & Key feature & Evaluation approach & Datasets & Application Area \\
\hline Aguzzoli et al. [4] & $\begin{array}{l}\text { Present a logic-based approach for recommender sys- } \\
\text { tems }\end{array}$ & No & No & No \\
\hline Queiroz et al. [102] & $\begin{array}{l}\text { Focus on recommendations for groups, based on col- } \\
\text { laborative filtering and OWA operators }\end{array}$ & Difference of mean & EachMovie & No \\
\hline Cornelis et al. [32] & $\begin{array}{l}\text { Use fuzzy logic for modelling one and only item rec- } \\
\text { ommendations }\end{array}$ & No & No & E-government \\
\hline Castellano et al. [24] & $\begin{array}{l}\text { Collaborative recommender system that incorporates } \\
\text { a fuzzy linguistic approach }\end{array}$ & No & No & $\begin{array}{l}\text { Academic Orien- } \\
\text { tation }\end{array}$ \\
\hline $\begin{array}{l}\text { Al-Shamri and Al-Ashwal } \\
\text { [6] }\end{array}$ & $\begin{array}{l}\text { Fuzzy-weighted Pearson correlation coefficient for } \\
\text { collaborative recommender systems }\end{array}$ & MAE, PCP, and Coverage & Movielens & No \\
\hline Zhang et al. [155] & $\begin{array}{l}\text { Hybrid recommendation approach which combines } \\
\text { fuzzy extensions of user-based and item-based collab- } \\
\text { orative filtering }\end{array}$ & MAE & Movielens & $\begin{array}{l}\text { Mobile products } \\
\text { and services rec- } \\
\text { ommendation }\end{array}$ \\
\hline Wang et al. [134] & $\begin{array}{l}\text { Propose a new fuzzy similarity measure-based recom- } \\
\text { mendation approach that only relies on rating values }\end{array}$ & MAE & Movielens & No \\
\hline Zhang et al. [154] & $\begin{array}{l}\text { New method to measure triangular fuzzy number, ap- } \\
\text { plied in collaborative filtering }\end{array}$ & MAE & Movielens & No \\
\hline Cheng and Wang [30] & $\begin{array}{l}\text { Fuzzy recommender system based on the integration } \\
\text { of subjective preferences and objective information. } \\
\text { The preferences are presented through a fuzzy lin- } \\
\text { guistic model }\end{array}$ & MAE, Prec/Recall/F1 & $\begin{array}{l}\text { Movielens+IMDb, } \\
\text { Yahoo Movies }\end{array}$ & No \\
\hline Reformat and Yager [105] & $\begin{array}{l}\text { Collaborative recommendation supported by } \\
\text { Pythagorean fuzzy sets }\end{array}$ & No & Scenario of use & No \\
\hline $\begin{array}{l}\text { Ladyzynski and Grze- } \\
\text { gorzewski [67] }\end{array}$ & $\begin{array}{l}\text { Quantify similarity between preferences through in- } \\
\text { tuitionistic fuzzy sets }\end{array}$ & Specific accuracy metric & $\begin{array}{l}\text { Semi-synthetic } \\
\text { labelled ranking } \\
\text { datasets }\end{array}$ & No \\
\hline Son and Thong [118] & $\begin{array}{l}\text { Present single-criterion and multi-criteria recommen- } \\
\text { dation approaches supported by intuitionistic fuzzy } \\
\text { sets }\end{array}$ & MAE and time cost & $\begin{array}{l}\text { Well-known pub- } \\
\text { lic datasets in the } \\
\text { health domain }\end{array}$ & $\begin{array}{l}\text { Medical diagno- } \\
\text { sis }\end{array}$ \\
\hline $\mathrm{Hu}[51]$ & $\begin{array}{l}\text { Uses the indifference relation to measure similarity } \\
\text { in multi-criteria collaborative filtering supported by } \\
\text { single-layer perceptron }\end{array}$ & Precision and time cost & $\begin{array}{l}\text { Gathered by the } \\
\text { authors }\end{array}$ & $\begin{array}{l}\text { Group-buying } \\
\text { website }\end{array}$ \\
\hline Hu et al. [52] & $\begin{array}{l}\text { Propose a similarity function that combines grey rela- } \\
\text { tional analysis with the Choquet fuzzy integral }\end{array}$ & $\begin{array}{l}\text { Ranking accuracy, MAE, } \\
\text { RMSE }\end{array}$ & Yahoo Movies! & No \\
\hline $\begin{array}{l}\text { Menhaj and Jamalzehi } \\
\text { [85] }\end{array}$ & $\begin{array}{l}\text { Propose a proximity-based similarity measure con- } \\
\text { taining a fuzzy inference system that depends on ho- } \\
\text { mophily correlation and influence correlation }\end{array}$ & Prec/Recall/F1 & Movielens & No \\
\hline Castro et al. [26] & $\begin{array}{l}\text { A group recommender system by combining collab- } \\
\text { orative filtering, fuzzy preference relations, and con- } \\
\text { sensus reaching process }\end{array}$ & AUC and Precision & Movielens & No \\
\hline Yera Toledo et al. [149] & $\begin{array}{l}\text { Managing natural noise in recommender systems, by } \\
\text { building user, item and rating profiles, and finding } \\
\text { contradictions between them }\end{array}$ & $\mathrm{MAE} / \mathrm{F} 1$ & $\begin{array}{l}\text { Movielens, } \\
\text { MovieTweeting, } \\
\text { Netflix }\end{array}$ & No \\
\hline
\end{tabular}




$$
\operatorname{sim}(x, y)=\frac{\sum_{s \in S_{x, y}} \int_{0}^{1}\left[\left(r_{x, S_{\alpha}}^{-}-r_{x_{\alpha}}^{-}\right)\left(r_{y, S_{\alpha}}^{-}-r_{y_{\alpha}}^{-}\right)+\left(r_{x, S_{\alpha}}^{+}-r_{x_{\alpha}}^{+}\right)\left(r_{y, S_{\alpha}}^{+}-r_{y_{\alpha}}^{+}\right)\right] d \alpha}{\left.\sqrt{\sum_{s \in S_{x, y}}\left(\int_{0}^{1}\left[\left(r_{x, S_{\alpha}}^{-}-r_{x_{\alpha}}^{-}\right)+\left(r_{x, S_{\alpha}}^{+}-r_{x_{\alpha}}^{+}\right)\right] d \alpha\right)^{2}} \sqrt{\sum_{s \in S_{x, y}}\left(\int_{0}^{1}\left[\left(r_{y, S_{\alpha}}^{-}-r_{y_{\alpha}}^{-}\right)+\left(r_{y, S_{\alpha}}^{+}-r_{y_{\alpha}}^{+}\right)\right] d \alpha\right.}\right)^{2}}
$$

and $r_{y_{\alpha}}$ are the average rating of the users of $S_{x, y}$ on $x$ and $y$ respectively.

Recently, other fuzzy modelling approaches, such as intuitionistic fuzzy sets, have been used for modelling users and items similarities [67, 118]. Moreover, in the last few years, some authors have combined fuzzy concepts with other computational intelligence techniques to compose similarity measures $[51,52,85]$.

In addition, there have been detected two research works focused on group recommendation supported by fuzzy concepts and regarding only user ratings, specifically proposing a Collective Fuzzy Preference Relation obtained through OWA operators [102], and proposing a consensus-driven recommender system supported by fuzzy techniques [26].

Eventually, it has been presented a fuzzy approach for managing the noise unintentionally introduced by human beings when they are eliciting preferences in collaborative recommender systems (i.e. natural noise $[25,148]$ ), using only rating values [149]. Specifically, it focuses on building fuzzy profiles of users, items, and ratings and therefore compares such profiles in order to find and correct noisy preferences by using an associated noise degree calculated from the fuzzy profiles.

\section{Collaborative filtering incorporating demographic} information and other users' and items' features. Several works have focused on enriching similarity functions with items' attributes or demographic information. Table 3 presents an exhaustive analysis of approaches with demographic information and other users' and items' features in collaborative filtering.

In Son [117], it is presented a definition of fuzzy recommender systems as an extension of recommender systems with the fuzzy similarity calculated based on the users' demographic data instead of the crisp user-based degree. This research proposes a user-user comparison function, Eq. (10), that con- siders a weighted sum of the Pearson correlation value between two user profiles (HSD measure) and a similarity value considering users' demographic profiles, presented in Eq. (11) (FSD).

$$
\operatorname{SIM}(a, b)=\alpha * F S D(a, b)+\beta * H S D(a, b)
$$

$$
F S D(a, b)=1-\sum_{i=1}^{l} w_{i} *\left|a_{i}-b_{i}\right|
$$

In Eq. (11), $a_{i}$ and $b_{i}$ are membership values characterizing demographic attributes (e.g. age, education, number of children, living standard), $l$ is the number of attributes, and $w_{i}$ is the corresponding attribute weight.

This scheme has been used and extended by most of contributions belonging to this group.

Eventually, new approaches have been recently proposed for modelling fuzzy tree-structured user preferences usually associated to business-tobusiness scenarios [138], and to an e-learning activities recommendation system [139]. These methods incorporate similarity measures for comparing trees, by considering all the information on tree structures, node attributes at the semantic level, and weights. Both cases then developed approaches for recommending such tree-structured items.

Collaborative filtering and trust. Trust networks have contributed to the success of recommender systems by users' recommendations, through the judgement of trusted sources/agents that have evaluated or experienced them (Fig. 13). Such information has been usually integrated into memory-based collaborative filtering approaches. 
Table 3. Incorporating demographic information and other item's features

\begin{tabular}{|c|c|c|c|c|}
\hline Papers & Key feature & Evaluation approach & Datasets & Application Area \\
\hline $\begin{array}{l}\text { Al-Shamri and Bharadwaj } \\
\text { [7] }\end{array}$ & $\begin{array}{l}\text { Use the fuzzy concordance/discordance principle to } \\
\text { support the similarity function of a recommender sys- } \\
\text { tem }\end{array}$ & MAE and Coverage & Movielens & No \\
\hline $\begin{array}{l}\text { Al-Shamri and Bharadwaj } \\
\text { [8] }\end{array}$ & $\begin{array}{l}\text { Fuzzy-genetic approach to recommender systems, } \\
\text { that uses fuzzy logic for modelling the users' demo- } \\
\text { graphic information }\end{array}$ & MAE and Coverage & Movielens & No \\
\hline Li et al. [71] & $\begin{array}{l}\text { Define a semantic distance between two fuzzy sets, } \\
\text { and apply it in a collaborative filtering }\end{array}$ & MAE & Movielens & No \\
\hline $\begin{array}{ll}\text { Ashkezari-T } & \text { and } \\
\text { Akbarzadeh-T [10] } & \end{array}$ & $\begin{array}{l}\text { Use genre-based information in a hybrid fuzzy- } \\
\text { bayesian network-based collaborative RS }\end{array}$ & $\begin{array}{l}\text { MAE, } \\
\text { Coverage }\end{array}$ & Movielens & No \\
\hline Kant and Bharadwaj [57] & $\begin{array}{l}\text { Fuzzy collaborative filtering approach considering } \\
\text { membership functions. Hybridized with a content- } \\
\text { based algorithm }\end{array}$ & MAE and Coverage & Movielens & No \\
\hline Son [117] & $\begin{array}{l}\text { Proposes a novel hybrid user-based method that inte- } \\
\text { grates fuzzy similarity degrees between users based } \\
\text { on the demographic data }\end{array}$ & $\begin{array}{l}\text { Accuracy metrics. Time } \\
\text { cost }\end{array}$ & $\begin{array}{l}\text { Movielens, } \\
\text { Bookcrossing }\end{array}$ & $\begin{array}{l}\text { Football results } \\
\text { prediction }\end{array}$ \\
\hline Wu et al. [138] & $\begin{array}{l}\text { Modelling fuzzy tree-structured user preferences usu- } \\
\text { ally associated to business-to-business scenarios }\end{array}$ & MAE, Prec/Recall/F1 & $\begin{array}{l}\text { Movielens+HetRec, } \\
\text { and a non-public } \\
\text { dataset }\end{array}$ & $\begin{array}{l}\text { Business-to- } \\
\text { business scenar- } \\
\text { ios }\end{array}$ \\
\hline Wu et al. [139] & $\begin{array}{l}\text { Propose an e-learning activities recommender system, } \\
\text { composed by a fuzzy tree-structured learning activity } \\
\text { model and a learner profile model }\end{array}$ & MAE & $\begin{array}{l}\text { Movielens. Also } \\
\text { a scenario of use }\end{array}$ & $\begin{array}{l}\text { E-learning rec- } \\
\text { ommendation }\end{array}$ \\
\hline
\end{tabular}

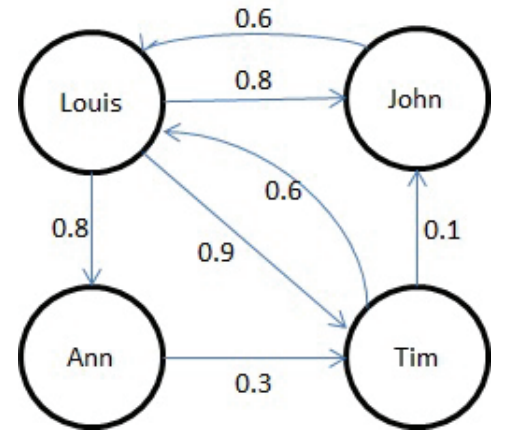

Fig. 13. Simple trust network.

Specifically, Victor et al. [130] propose the use of a user trust network model for recommender systems, in which trust is represented as a (trust,distrust)-pair. The model preserves valuable information such as gradual trust, distrust, ignorance, and inconsistency.

Bharadwaj and Al-Shamri [17] propose fuzzy computational models for trust and reputation concepts. Specifically, Fig. 14 presents the satisfied and unsatisfied fuzzy subsets presented by such authors, which are used for defining four values associated for any two users: satisfied-satisfied (SS), unsatisfied-unsatisfied (UU), satisfied-unsatisfied (SU), and unsatisfied-satisfied (US). These values are used to define agreement and disagreement between users, according to Eqs. (12) and (13), which are subsequently used for calculating reciprocity, Eq. (14).

$$
\begin{gathered}
\operatorname{agr}\left(a_{i}, a_{j}\right)=\frac{S S\left(a_{i}, a_{j}\right)+U U\left(a_{i}, a_{j}\right)}{2} \\
\operatorname{disagr}\left(a_{i}, a_{j}\right)=\frac{S U\left(a_{i}, a_{j}\right)+U S\left(a_{i}, a_{j}\right)}{2} \\
\operatorname{rec}\left(a_{i}, a_{j}\right)=\left(1-\operatorname{disagr}\left(a_{i}, a_{j}\right)\right) \operatorname{agr}\left(a_{i}, a_{j}\right)
\end{gathered}
$$

This reciprocity value is combined with a reliability value (also detailed by Bharadwaj and AlShamri [17]), to obtain a more accurate reciprocity value (Eq. 15)

$$
\operatorname{recip}\left(a_{i}, a_{j}\right)=\operatorname{reliab}\left(a_{i}, a_{j}\right) * \operatorname{rec}\left(a_{i}, a_{j}\right)
$$

Such a value is combined with an experience value (Eq. (16), (17), and (18)) in order to finally calculate the trust value (Eq. 19), where $n_{i}$ is the 
number of interactions of the user $i$, and $M$ is the number of users.

$$
\begin{gathered}
\operatorname{conf}_{a_{i}}\left(a_{j}\right)=\frac{n_{j}}{\max \left(n_{i}, n_{j}\right)} \\
\operatorname{ex}\left(a_{j}\right)=\frac{N_{j}}{\max \left(n_{1}, \ldots, n_{M}\right)} \\
\operatorname{Exper}_{a_{i}}\left(a_{j}\right)=\operatorname{conf}_{a_{i}}\left(a_{j}\right) * \operatorname{ex}_{a_{j}} \\
\text { trust }_{a_{i}}\left(a_{j}\right)=\frac{2 * \operatorname{Exper}_{a_{i}}\left(a_{j}\right) * \operatorname{reci}\left(a_{i}, a_{j}\right)}{\operatorname{Exper}_{a_{i}}\left(a_{j}\right)+\operatorname{recip}\left(a_{i}, a_{j}\right)}
\end{gathered}
$$

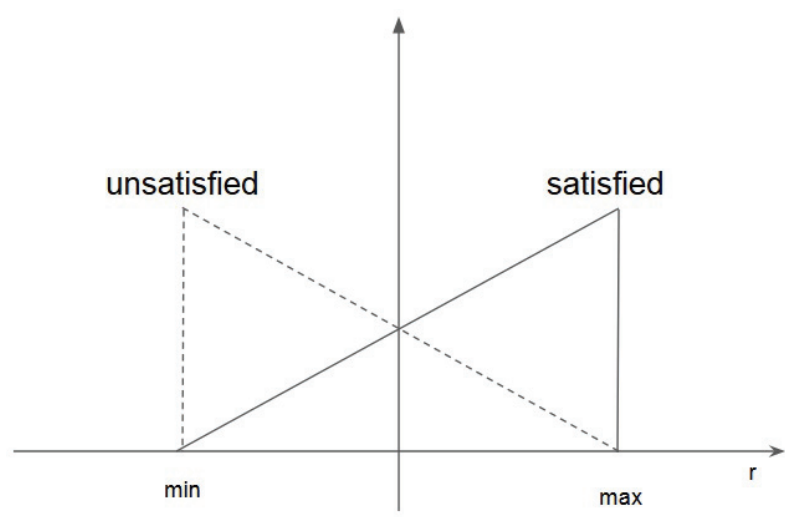

Fig. 14. Membership functions of satisfied and unsatisfied fuzzy subsets, defined by Bharadwaj and Al-Shamri [17].

Additionally, the reputation is modelled as a fuzzy extension of the beta reputation model [56], combined with an OWA operator [144].

This approach has been further extended by considering fuzzy distrust propagation operators [58], and hybridizations with case-based reasoning [127], and with context-aware recommendation [72].

Similarly, other approaches considering trust in memory-based collaborative filtering scenarios were developed at Birtolo and Ronca [19] and Bedi and Vashisth [15].

Table 4 presents further analysis of the referred research works, by additionally including other important aspects such as evaluation approaches, used datasets, and application areas.

\subsubsection{Discussion}

The previous analysis leads to the identification of the following strengths and weaknesses related to the use of fuzzy tools in memory-based collaborative filtering.

\section{Strengths:}

- The works present suitable evaluation protocols, by using public and popular datasets and implementing diverse evaluation metrics, proving the effectiveness of the fuzzy modelling in recommendation scenarios. Some works (around 30\%) have been also focused on practical scenarios.

- Research associated to trees as a data structure has been mainstream since several decades ago. Therefore, it could be a fruitful source of new ideas for extending the presented works focused on recommending tree-structured items.

\section{Weaknesses:}

- More than $60 \%$ of the works that use public datasets for experimentation, are focused only on Movielens dataset, discarding other well-known datasets for the rating prediction task with larger rating ranges (e.g. MovieTweeting, Jester), where the use of fuzzy logic could lead to a larger improvement of the recommendation approaches.

- The development of fuzzy extensions for similarity measures between users/items, takes as basis very traditional measures such as Pearson and cosine, having a lack of works on fuzzy extensions for emerging similarity approaches well-received by the research community recently $[20,74]$.

- Around $50 \%$ of the works assume the availability of additional information beyond preference values, which is not always available, for building fuzzy-supported similarity measures.

- There is a lack of suitable datasets that fully contain tree-structured items.

- Only one research work uses alternatives evaluation metrics such as diversity and serendipity. 
Table 4. Collaborative filtering with trust

\begin{tabular}{|c|c|c|c|c|}
\hline Papers & Key feature & Evaluation approach & Datasets & $\begin{array}{l}\text { Application } \\
\text { Area }\end{array}$ \\
\hline Victor et al. [130] & $\begin{array}{l}\text { Propose a user trust network model preserving valu- } \\
\text { able information such as gradual trust, distrust, igno- } \\
\text { rance, and inconsistency }\end{array}$ & No & No & No \\
\hline $\begin{array}{l}\text { Bharadwaj and Al-Shamri } \\
\text { [17] }\end{array}$ & $\begin{array}{l}\text { Propose fuzzy computational models for trust and } \\
\text { reputation concepts }\end{array}$ & MAE, Coverage & Movielens & No \\
\hline $\begin{array}{l}\text { Tyagi and Bharadwaj } \\
{[127]}\end{array}$ & $\begin{array}{l}\text { Combine case-based reasoning, collaborative filter- } \\
\text { ing, and the model proposed by Bharadwaj and Al- } \\
\text { Shamri [17] }\end{array}$ & MAE, RMSE, Coverage & Movielens & No \\
\hline Birtolo and Ronca [19] & $\begin{array}{l}\text { Integrate trust relationships between users, into a } \\
\text { fuzzy c-means scenario }\end{array}$ & RMSE, Coverage & $\begin{array}{l}\text { Movielens, Jester, Epin- } \\
\text { ions, and a non-public e- } \\
\text { commerce dataset }\end{array}$ & No \\
\hline Kant and Bharadwaj [58] & $\begin{array}{l}\text { Extend Bharadwaj and Al-Shamri [17] by considering } \\
\text { fuzzy distrust propagation operators }\end{array}$ & MAE, Coverage & Movielens & No \\
\hline Bedi and Vashisth [15] & $\begin{array}{l}\text { Propose a new fuzzy and argumentation-based trust } \\
\text { model integrated within the practical reasoning of } \\
\text { agents in a recommender systems scenario }\end{array}$ & $\begin{array}{l}\text { Prec/Recall/F1, Fall-Out, } \\
\text { EPC (Novelty) }\end{array}$ & Gathered by the authors & Books \\
\hline Linda and Bharadwaj [72] & $\begin{array}{l}\text { Exploit fuzzy trust among users, by incorporating a } \\
\text { context-aware approach }\end{array}$ & MAE, Coverage & $\begin{array}{l}\text { Two non-public context- } \\
\text { aware datasets }\end{array}$ & No \\
\hline
\end{tabular}

\subsection{Model-based collaborative filtering with fuzzy tools}

This section is devoted to present the contributions focused on incorporating fuzzy approaches in model-based collaborative filtering recommendation. Additionally, it also discusses the global strengths and weaknesses of the analysed works.

\subsubsection{Proposals}

Unlike memory-based approaches, it is more difficult the generalization of a common scheme for model-based collaborative filtering (see Fig. 2), because it depends on the computational model used for recommendation generation. In this way, Fig. 15 presents a synthetic overview on the computational models that, regarding fuzzy logic, are used to complete this task. Specifically, the research works presented at this section will be composed in four categories: 1) Fuzzy clustering, 2) Fuzzy inferencebased approaches, 3) Fuzzy association rules and 4) Fuzzy bayesian approaches.

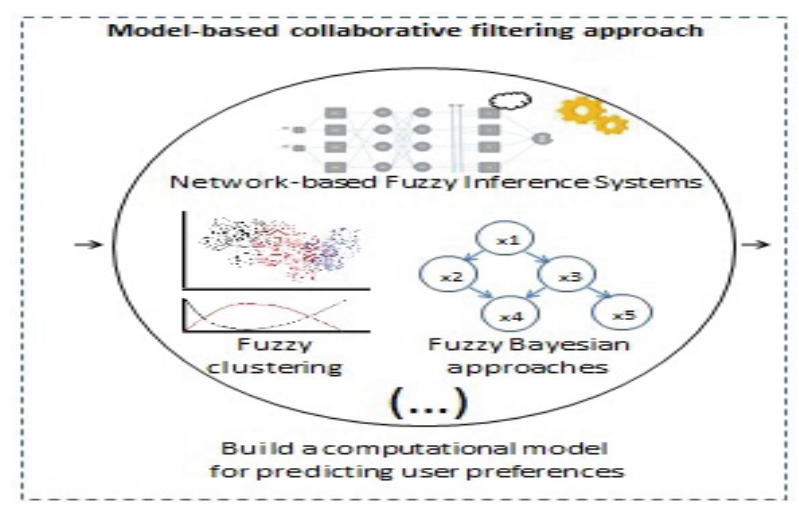

Fig. 15. Fuzzy model-based collaborative filtering

Fuzzy clustering. Several research works use the fuzzy clustering inside the recommendation approach as an intermediate step (see Tables 5 and 6), for later applying traditional algorithms such as item-item memory-based collaborative filtering [112] on specific clusters, in order to improve some recommendation performance measures such as accuracy, response time, or diversity.

In this way, a popular clustering algorithm widely employed in such scenarios is the fuzzy cmeans algorithm (see Fig. 16) [16]. This algo- 
Table 5. Fuzzy clustering in recommender systems (1)

\begin{tabular}{|c|c|c|c|c|}
\hline Papers & Key feature & Evaluation protocol & Datasets & Application Area \\
\hline Suryavanshi et al. [121] & $\begin{array}{l}\text { Use relational fuzzy subtractive clustering and then } \\
\text { mine association rules within individual clusters }\end{array}$ & $\mathrm{F} 1$ & $\begin{array}{l}\text { Web server logs } \\
\text { (non-public) }\end{array}$ & Web usage data \\
\hline Schlecht and Gaul [114] & $\begin{array}{l}\text { Combine collaborative filtering with fuzzy two-mode } \\
\text { clustering }\end{array}$ & $\begin{array}{l}\text { Average absolute devia- } \\
\text { tion }\end{array}$ & Movielens & No \\
\hline Min and Han [86] & $\begin{array}{l}\text { Consider the time dimension in data for finding fuzzy } \\
\text { clusters at different time frames }\end{array}$ & MAE & EachMovie & No \\
\hline Honda et al. [48] & $\begin{array}{l}\text { Estimation of local linear models that performs a si- } \\
\text { multaneous application of fuzzy clustering and prin- } \\
\text { cipal component analysis }\end{array}$ & MAE and ROC analysis & Movielens & No \\
\hline Wang [133] & $\begin{array}{l}\text { Combines a smooth filling technique with fuzzy c- } \\
\text { means clustering }\end{array}$ & MAE & Movielens & No \\
\hline Chen et al. [29] & $\begin{array}{l}\text { Fill unknown ratings based on rough set theory, and } \\
\text { use fuzzy clustering to compute user similarity and } \\
\text { obtain nearest neighbourhoods }\end{array}$ & MAE & Movielens & No \\
\hline Mittal et al. [87] & $\begin{array}{l}\text { Apply first fuzzy c-means for clustering data based on } \\
\text { attributes, and then k-means for clustering users based } \\
\text { on ratings }\end{array}$ & No & Scenario of use & No \\
\hline Liu and Yin [73] & $\begin{array}{l}\text { Use fuzzy c-means to generate multiple recommen- } \\
\text { dation agents which take the place of the active user's } \\
\text { neighbours }\end{array}$ & MAE & Movielens & No \\
\hline Honda et al. [49] & $\begin{array}{l}\text { User-item co-clusters are extracted in a sequential } \\
\text { way via a structural balancing technique }\end{array}$ & $\begin{array}{l}\text { Cluster validation tech- } \\
\text { niques }\end{array}$ & Movielens & No \\
\hline Fang and Zheng [39] & $\begin{array}{l}\text { Collaborative filtering recommendation based on } \\
\text { fuzzy formal concept analysis, for conceptual cluster- } \\
\text { ing }\end{array}$ & MAE and RMSE & Movielens & No \\
\hline Fenza et al. [40] & $\begin{array}{l}\text { Use fuzzy c-means for clustering users and points-of- } \\
\text { interest (POI), for POI recommendation }\end{array}$ & MAE and RMSE & $\begin{array}{l}\text { Data gathered by } \\
\text { the researchers }\end{array}$ & Tourist guidance \\
\hline $\begin{array}{l}\text { Treerattanapitak } \quad \text { and } \\
\text { Jaruskulchai [125] }\end{array}$ & $\begin{array}{l}\text { New exponential fuzzy clustering (XFCM) algorithm } \\
\text { by reformulating the clustering objective function } \\
\text { with an exponential equation }\end{array}$ & MAE & Movielens & No \\
\hline Esfahani and Alhan [38] & $\begin{array}{l}\text { Use items' features in a content-based scenario to } \\
\text { cluster items and users using fuzzy c-means method }\end{array}$ & No & No & $\begin{array}{l}\text { Book recommen- } \\
\text { dation }\end{array}$ \\
\hline Verma et al. [129] & $\begin{array}{l}\text { Use fuzzy c-means clustering as a previous step for } \\
\text { the application of the item-based collaborative filter- } \\
\text { ing algorithm }\end{array}$ & MAE and RMSE & Movielens & No \\
\hline Son et al. [119] & $\begin{array}{l}\text { Use of the fuzzy geographically clustering to solve } \\
\text { the cold-start problem in recommender systems }\end{array}$ & MAE and RMSE & Movielens & No \\
\hline Devi and Venkatesh [35] & $\begin{array}{l}\text { Combine a kernel fuzzy c-means clustering approach } \\
\text { with a Radial Basis Function Network }\end{array}$ & MAE, Prec/Recall & Movielens & No \\
\hline Bilge and Polat [18] & $\begin{array}{l}\text { Show how to apply clustering schemes in collabora- } \\
\text { tive filtering, preserving users' confidentiality }\end{array}$ & MAE, Online time & Movielens & No \\
\hline Komkhao et al. [64] & $\begin{array}{l}\text { Incremental approach including fuzzy clustering, } \\
\text { where membership degrees to clusters are expressed } \\
\text { by the Mahalanobis radial basis function. }\end{array}$ & MAE & Movielens & $\begin{array}{l}\text { Movie recom- } \\
\text { mendation }\end{array}$ \\
\hline Xu and Watada [143] & $\begin{array}{l}\text { Proposal of new membership functions for user pro- } \\
\text { file fuzzification, for alternative rating scales }\end{array}$ & MAE & Movielens & No \\
\hline Wu et al. [141] & $\begin{array}{l}\text { Use fuzzy clustering as a previous step for the user- } \\
\text { based collaborative filtering algorithm }\end{array}$ & MAE & Movielens & No \\
\hline Xu et al. [142] & $\begin{array}{l}\text { Collaborative filtering algorithm based on user fuzzy } \\
\text { clustering to generate optimized stock set, based on } \\
\text { money flow model }\end{array}$ & $\begin{array}{l}\text { Performance measures re- } \\
\text { lated to the corresponding } \\
\text { domain }\end{array}$ & $\begin{array}{l}\text { Real stock market } \\
\text { data }\end{array}$ & $\begin{array}{l}\text { Stock set recom- } \\
\text { mendation }\end{array}$ \\
\hline
\end{tabular}


Table 6. Fuzzy clustering in recommender systems (2)

\begin{tabular}{|c|c|c|c|c|}
\hline Papers & Key feature & $\begin{array}{l}\text { Evaluation ap- } \\
\text { proach }\end{array}$ & Datasets & Application Area \\
\hline $\begin{array}{l}\text { Thong and Son } \\
{[123]}\end{array}$ & $\begin{array}{l}\text { Combine picture fuzzy clustering and intuitionistic } \\
\text { recommender systems for medical diagnosis }\end{array}$ & $\begin{array}{l}\text { MAE and time } \\
\text { cost }\end{array}$ & $\begin{array}{l}\text { Well-known public datasets in the } \\
\text { health domain }\end{array}$ & $\begin{array}{l}\text { Medical diagno- } \\
\text { sis }\end{array}$ \\
\hline Bai et al. [11] & $\begin{array}{l}\text { Apply fuzzy clustering for calculating users' confi- } \\
\text { dence score }\end{array}$ & $\begin{array}{l}\text { RMSE and MAP } \\
\text { (Mean Average } \\
\text { Precision) }\end{array}$ & $\begin{array}{l}\text { DBLP and Microsoft Academic ci- } \\
\text { tation data }\end{array}$ & $\begin{array}{l}\text { Research papers } \\
\text { recommendation }\end{array}$ \\
\hline $\begin{array}{l}\text { Veloso et al. } \\
{[128]}\end{array}$ & $\begin{array}{l}\text { Incorporate user-based fuzzy c-means clustering to } \\
\text { improve scalability }\end{array}$ & $\begin{array}{l}\text { MAE, RMSE, } \\
\text { Prec/Recall/F1 }\end{array}$ & Movielens+HetRec & $\begin{array}{l}\text { Media content } \\
\text { recommendation }\end{array}$ \\
\hline $\begin{array}{l}\text { Vimali and Taj } \\
\text { [131] }\end{array}$ & $\begin{array}{l}\text { Use fuzzy c-mean algorithm for consolidating ser- } \\
\text { vices' data before the application of a memory-based } \\
\text { collaborative filtering algorithm }\end{array}$ & No & No & $\begin{array}{l}\text { Service recom- } \\
\text { mendation }\end{array}$ \\
\hline $\begin{array}{l}\text { Qiao and Zhang } \\
{[101]}\end{array}$ & $\begin{array}{l}\text { Propose a recommendation algorithm based on user } \\
\text { context clustering, regarding timeliness }\end{array}$ & MAE & Movielens & No \\
\hline He and Fan [45] & $\begin{array}{l}\text { Propose an improved collaborative filtering recom- } \\
\text { mendation based on co-clustering of users and items }\end{array}$ & No & No & No \\
\hline Guan et al. [43] & $\begin{array}{l}\text { Propose the Intuitionistic Fuzzy Agglomerative Hi- } \\
\text { erarchical Clustering (IFAHC) algorithm for recom- } \\
\text { mendation using social tagging }\end{array}$ & Scenario of use & No & No \\
\hline $\begin{array}{l}\text { Koohi and Kiani } \\
{[66]}\end{array}$ & $\begin{array}{l}\text { Apply fuzzy c-means clustering to user-based collab- } \\
\text { orative filtering }\end{array}$ & $\begin{array}{l}\text { Prec/Recall, Ac- } \\
\text { curacy }\end{array}$ & Movielens & No \\
\hline $\begin{array}{l}\text { Ramezani and } \\
\text { Yaghmaee [103] }\end{array}$ & $\begin{array}{l}\text { Group the vectors of each video by k-means and fuzzy } \\
\text { c-means clustering }\end{array}$ & Accuracy & $\begin{array}{l}\text { KTH, UCF YouTube (UCFYT), } \\
\text { UCF Sport and HMDB action } \\
\text { datasets }\end{array}$ & $\begin{array}{l}\text { Video recom- } \\
\text { mendation }\end{array}$ \\
\hline $\begin{array}{ll}\text { Katarya } & \text { and } \\
\text { Verma [61] } & \end{array}$ & $\begin{array}{l}\text { Combine the particle swarm optimization technique } \\
\text { with fuzzy c-means clustering to find a more precise } \\
\text { neighbourhood for the active user }\end{array}$ & MAE & Movielens & No \\
\hline
\end{tabular}

rithm works on a matrix $U_{N x C}$ containing the membership degree for all objects in the set $N$, in relation with the clusters' centroids in $C$. Once such a matrix is initialized (which could be done through diverse strategies, including randomly), at each $k^{\text {th }}$ step, each centroid $c_{j}$ is calculated according to $\mathrm{Eq}$ (20). Afterwards, the membership values $u_{i j}$ (object $i$ for center $c_{j}$ ) are updated according to the new calculated centroids , Eq. (21). This process is repeated (see loop in Fig. 16) until matrix $U$ does not change substantially in relation to the previous iteration, Eq. (22). In the equations, $\varepsilon$ is a stop threshold, $m$ is a fuzziness exponent, and $\|*\|$ is a norm expressing the similarity between any measured datum and the centroid.

$$
\begin{gathered}
c_{j}=\frac{\sum_{i=1}^{N} u_{i j}^{m} * x_{i}}{\sum_{i=1}^{N} u_{i j}^{m}} \\
u_{i j}=\frac{1}{\sum_{o=1}^{C}\left(\frac{\left\|x_{i}-c_{j}\right\|}{\left\|x_{i}-c_{o}\right\|}\right)^{\frac{2}{m-1}}}
\end{gathered}
$$

$$
\left\|U^{(k+1)}-U^{(k)}\right\|<\varepsilon
$$

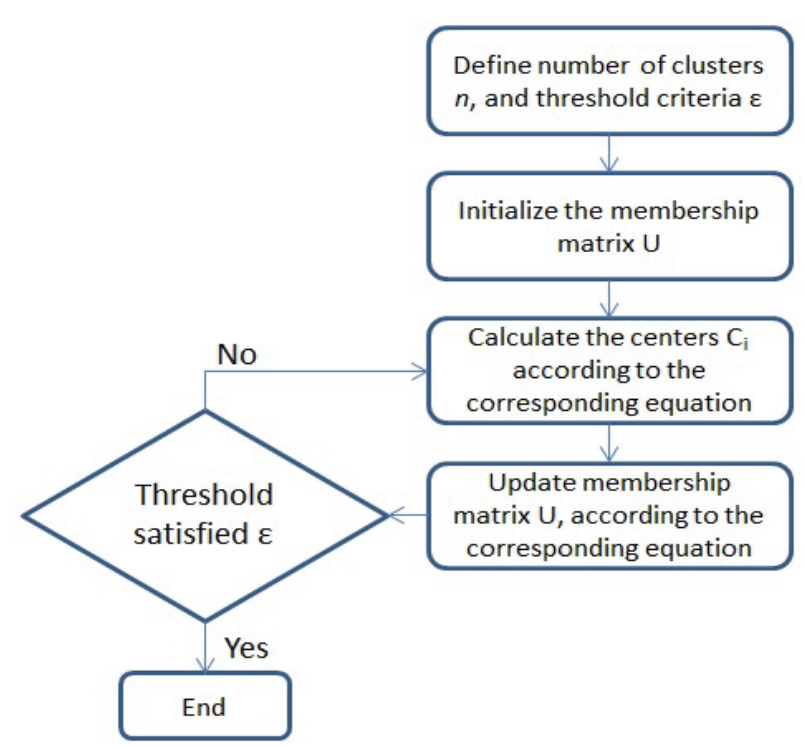

Fig. 16. Overview of the fuzzy c-means algorithm 
Regarding both ratings and additional items' information, several works have employed the fuzzy c-means clustering $[11,38,40,66,73,87,101$, $103,128,129,131,141,142]$, and also similar approaches such as relational fuzzy subtractive clustering [121], co-clustering [45, 49, 114, 133], picture fuzzy clustering [123], folksonomy-focused intuitionistic fuzzy agglomerative hierarchical clustering [43], fuzzy geographical clustering [119], linear fuzzy clustering [48], and other fuzzy clustering approaches [18, 29, 35, 39, 61, 64, 143].

In this way, some research works should be remarked because they take advantages of specific features related to the data in recommender systems such as the temporal information or neighbourhood models, for the development of the clustering approaches. A relevant approach is the inclusion of the time dimension to the original input data of collaborative filtering for finding the fuzzy cluster at different time frames, proposing a dynamic membership degree and determining the neighbourhood for a given user based on the dynamic fuzzy cluster [86]. On the other hand, Treerattanapitak and Jaruskulchai [125] propose a new exponential fuzzy clustering (XFCM) algorithm by reformulating the clustering objective function with an exponential equation in order to improve the method in relation to membership calculation. This transformation allows a more aggressive exclusion of irrelevant data from the clusters, improving in this way other fuzzy c-means alternatives.

Tables 5 and 6 present a deeper analysis of the particularities of the research works referred in this section.

Fuzzy inference-based approaches. This subsection is devoted to present some proposals based on fuzzy inference-based approaches, some of them network-supported approaches (see Table 7), which can be classified as model-based collaborative filtering, according to Bobadilla et al. [21].

Kim et al. [62] present an early work proposing a collaborative filtering approach that is based on improved fuzzy associative memories. The approach initially asks users to rate a gauge sets of items, processes the users' ratings, and therefore suggests a set of suitable items as a recommendation output. The proposal is based on the readjustment of the connection weights between the nodes of the fuzzy associative memory using error back propagation, for simplifying the fuzzy rules. The proposal was tested in the domain of retrieving technical papers.

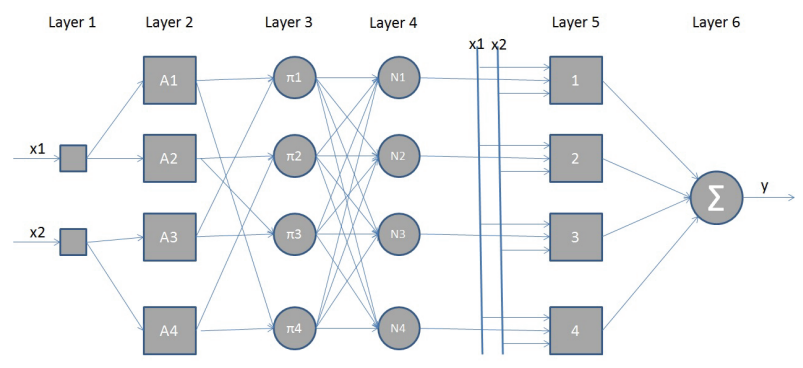

Fig. 17. ANFIS. layer 1: Input, layer 2:fuzzification, layer 3: rule, layer 4: normalization, layer 5: defuzzification, layer 6: output.

Afterwards, a more advanced approach were developed by Nilashi et al. [91], that presents a new model for multi-criteria collaborative filtering using an Adaptive-Network-based Fuzzy Inference System [54] (ANFIS, see Fig. 17 ) combined with subtractive clustering and high order singular value decomposition. The input parameters of the ANFIS model are the criteria over the movies, specifically acting, directing, story and visuals; and the overall rating stands for output, that is defined as the overall preference. In this direction, later these authors developed extensions of this work by implementing alternative clustering approaches, such as SelfOrganization Maps [93], and the Expectation Maximization algorithm [92].

Beyond these two key researches, other authors such as Chao et al. [27], Sobecki et al. [116], Jeon et al. [55], Nguyen and Duong [90] and Tiwari and Kaushik [124], have also developed more application-oriented recommendation approaches supported by fuzzy inference processes.

Fuzzy association rules-based approaches. In a different direction, it was also detected a group of works focused on the use of fuzzy association rule mining for supporting recommendation (Table 8). Such group is composed of the researches developed by Chen and Tai [28], Pinho Lucas et al. [98] 
Table 7. Fuzzy inference-based approaches

\begin{tabular}{|c|c|c|c|c|c|}
\hline Papers & Key feature & \multicolumn{2}{|c|}{ Evaluation approach } & Datasets & Application Area \\
\hline Kim et al. [62] & $\begin{array}{l}\text { Readjust the connection weights between the nodes of the } \\
\text { fuzzy associative memory using error back propagation, for } \\
\text { simplifying the fuzzy rules used for recommendation genera- } \\
\text { tion }\end{array}$ & MAE & & $\begin{array}{l}\text { Gathered by the } \\
\text { authors }\end{array}$ & $\begin{array}{l}\text { Retrieval of tech- } \\
\text { nical papers }\end{array}$ \\
\hline Chao et al. [27] & $\begin{array}{l}\text { Recommendation agent with a fuzzy inference engine for rec- } \\
\text { ommending e-learning resources }\end{array}$ & No & & No & $\begin{array}{l}\text { e-learning plat- } \\
\text { forms }\end{array}$ \\
\hline $\begin{array}{l}\text { Sobecki et al. } \\
{[116]}\end{array}$ & $\begin{array}{l}\text { Use demographic information for building membership func- } \\
\text { tions, and construct fuzzy inference rules }\end{array}$ & No & & No & $\begin{array}{l}\text { Cooking assis- } \\
\text { tance }\end{array}$ \\
\hline Jeon et al. [55] & $\begin{array}{l}\text { Manage the personal propensity of the users, and include a } \\
\text { fuzzy inference system }\end{array}$ & RMSE & & Netflix & No \\
\hline Nilashi et al. [91] & $\begin{array}{l}\text { Multi-criteria CF using ANFIS combined with subtractive } \\
\text { clustering and higher order singular value decomposition }\end{array}$ & $\begin{array}{l}\text { MAE, } \\
\text { Prec/Recall/F1, } \\
\text { erage }\end{array}$ & $\begin{array}{l}\text { RMSE, } \\
\text { Cov- }\end{array}$ & $\begin{array}{l}\text { Yahoo Movies, } \\
\text { Movielens }\end{array}$ & No \\
\hline Nilashi et al. [93] & Multi-criteria CF using self-organization maps & $\begin{array}{l}\text { MAE, } \\
\text { Prec/Recall/F1, } \\
\text { erage }\end{array}$ & $\begin{array}{l}\text { RMSE, } \\
\text { Cov- }\end{array}$ & $\begin{array}{l}\text { Yahoo Movies, } \\
\text { Movielens }\end{array}$ & No \\
\hline Nilashi et al. [92] & Multi-criteria $\mathrm{CF}$ using expectation maximization algorithm & $\begin{array}{l}\text { MAE, } \\
\text { Prec/Recall/F1, } \\
\text { erage }\end{array}$ & $\begin{array}{l}\text { RMSE, } \\
\text { Cov- }\end{array}$ & $\begin{array}{l}\text { Yahoo Movies, } \\
\text { Movielens }\end{array}$ & Tourism domain \\
\hline $\begin{array}{l}\text { Tiwari and } \\
\text { Kaushik [124] }\end{array}$ & $\begin{array}{l}\text { Use a fuzzy inference system that manages dimensions such as } \\
\text { traffic conditions, security, or suitable transportation }\end{array}$ & No & & $\begin{array}{l}\text { Gathered by the } \\
\text { authors }\end{array}$ & Tourist spots \\
\hline $\begin{array}{ll}\text { Nguyen } & \text { and } \\
\text { Duong [90] } & \end{array}$ & $\begin{array}{l}\text { Model-based collaborative filtering using a fuzzy neural net- } \\
\text { work to learn user's behaviours for video recommendation }\end{array}$ & MAE, RMSE & & Netflix & $\begin{array}{l}\text { Video recom- } \\
\text { mendation }\end{array}$ \\
\hline
\end{tabular}

Leung et al. [70], and Teng et al. [122]. Specifically, Leung et al. [70] introduce a collaborative filtering approach based on fuzzy association rules and multiple-level similarity. With this purpose, they fuzzify numeric ratings into three sets Like, Neutral and Dislike, and also incorporate rule's interestingness measures such as fuzzy support and fuzzy confidence.

Eventually, Banda and Bharadwaj [13] propose a novel collaborative tagging-based page recommendation algorithm using a fuzzy classifier. Specifically, they calculate the similarity of users in selecting tags and therefore use this information for finding the nearest neighbours of each user, and clustering them. The priority of tags and items for each user is then calculated for constructing a Nominal Label Matrix and Nominal Page Matrix; which are used for obtaining fuzzy rules that generate page recommendation.

Fuzzy bayesian approaches. de Campos et al. [33] propose a collaborative recommender system that combines probabilistic inference and fuzzy observations. Specifically, it involves three components: a mapping of the fuzzy ratings (input) to a probabilistic distribution; the use of probabilistic reasoning to compute the probability distribution over the expected vote; and the calculation of the user's vote (a fuzzy set).

Other approaches that also integrate fuzzy and bayesian concepts, have been proposed by Kant and Bharadwaj [59] and Zhang et al. [153].

Table 8 presents a further analysis of these works.

\subsubsection{Discussion}

The previous analysis leads to the identification of the following strengths and weaknesses related to fuzzy model-based collaborative filtering.

\section{Strengths:}

- A relatively high amount of research works within model-based collaborative filtering approaches 
Table 8. Fuzzy association rules-based and fuzzy bayesian approaches

\begin{tabular}{|c|c|c|c|c|}
\hline Papers & Key feature & $\begin{array}{l}\text { Evaluation } \\
\text { proach }\end{array}$ & Datasets & $\begin{array}{l}\text { Application } \\
\text { Area }\end{array}$ \\
\hline \multicolumn{5}{|c|}{ Fuzzy association rules-based approaches } \\
\hline Chen and Tai [28] & Use fuzzy association rules for classifying users & No & Scenario of use & No \\
\hline Leung et al. [70] & $\begin{array}{l}\text { Introduce a collaborative filtering approach based on fuzzy association } \\
\text { rules and multiple-level similarity }\end{array}$ & Recall & $\begin{array}{l}\text { Movielens, Jester, } \\
\text { EachMovie }\end{array}$ & No \\
\hline $\begin{array}{l}\text { Pinho Lucas et al. } \\
\text { [98] }\end{array}$ & $\begin{array}{l}\text { Fuzzy associative classification approach, focused on obtaining the pos- } \\
\text { sible groups to which the active user owns to }\end{array}$ & $\begin{array}{l}\text { Classification ac- } \\
\text { curacy, false pos- } \\
\text { itive rates }\end{array}$ & $\begin{array}{l}\text { Movielens, } \\
\text { Bookcrossing }\end{array}$ & No \\
\hline $\begin{array}{l}\text { Banda and } \\
\text { Bharadwaj [13] }\end{array}$ & $\begin{array}{l}\text { Novel collaborative tagging-based page recommendation algorithm us- } \\
\text { ing a fuzzy classifier. Find the nearest neighbours depending on the } \\
\text { similarity of users regarding selected tasks. }\end{array}$ & Hit ratio, recall & Movielens + HetRec & No \\
\hline Teng et al. [122] & $\begin{array}{l}\text { Fuzzy Analytical Hierarchy Process (FAHP)-based recommendation } \\
\text { method by fusing apriori rule mining }\end{array}$ & $\begin{array}{l}\text { Precision, } \\
\text { quency }\end{array}$ & $\begin{array}{l}\text { Gathered by the au- } \\
\text { thors }\end{array}$ & books \\
\hline \multicolumn{5}{|c|}{$\begin{array}{ll}\text { Fuzzy bayesian approaches } \\
\end{array}$} \\
\hline $\begin{array}{l}\text { de Campos et al. } \\
{[33]}\end{array}$ & $\begin{array}{l}\text { Combine probabilistic inference and fuzzy observations for proposing } \\
\text { a collaborative recommender system }\end{array}$ & $\begin{array}{l}\text { MAE, } \\
\text { Prec/Recall/F1 }\end{array}$ & Movielens & No \\
\hline $\begin{array}{l}\text { Kant and Bharad- } \\
\text { waj [59] }\end{array}$ & $\begin{array}{l}\text { A recommendation approach based on collaborative filtering and reclu- } \\
\text { sive methods, that incorporates a fuzzy naïve bayesian classifier }\end{array}$ & Prec/Recall/F1 & Movielens+IMDb & No \\
\hline Zhang et al. [153] & $\begin{array}{l}\text { Combine item-based collaborative filtering and a bayesian approach for } \\
\text { selecting suitable services, represented through trapezoidal fuzzy num- } \\
\text { ber }\end{array}$ & No & Scenario of use & $\begin{array}{l}\text { e- } \\
\text { government }\end{array}$ \\
\hline
\end{tabular}

with fuzzy tools (the $44 \%$ of all the reviewed papers), have proved that fuzzy versions of traditional learning paradigms, can be useful in recommendation scenarios.

- The opportunity for complementing the presented work focused on network-based fuzzy inference systems, with currently popular network-related paradigms such as deep learning [68].

\section{Weaknesses:}

- Diversity of approaches focused on very different recommendation scenarios. This fact makes difficult the development of a fair experimental comparison between the proposals.

- Most of the research works in fuzzy clustering (around 80\%), are limited to the direct application of a general-purposed fuzzy clustering algorithm (e.g. fuzzy c-means), disregarding the particularities of the recommender systems data and its possible influence on the development of the clustering approach.

- It seems that the success of fuzzy rules and fuzzy inference systems in recommender systems is usually associated to the management of users' and items' attributes, being only $14 \%$ of the works belonging to such groups, directly related to the management of preference values. This fact could decrease the impact of these approaches in relation with other kind of recommendation methods.

\section{Future research directions}

The previous sections discussed several weaknesses in the development of research works focused on the use of fuzzy approaches in recommender systems. Such weaknesses show some research gaps that can be considered as possible future trends and challenges for fuzzy based recommendation. Specifically, we identify four challenging areas that should be expanded in the coming future, for a better exploitation of fuzzy tools to improve the performance of recommender systems:

- Fuzzy common framework for further researches in recommender systems. Previously, we have referred several works such as $[117,134$, 152] that have made important contributions to this aim, but only present a partial solution of the problem because they have a lack of generalization in relation to typical recommendation scenar- 
ios, and in other cases the use of fuzzy tools is insufficient regarding its flexibility to represent user preferences. In addition, the absence of a common framework implies that emerging researches just reproduce previous results, because there is not a clear reference point to work with.

- Evaluation scenarios focused on fuzzy recommender systems. Even though many revised papers evaluate their proposals using public wellknown datasets, there are still works that need to gather their own data, and also works that did not perform any kind of experimental evaluation. In many cases this fact occurs either because of the lack of suitable datasets in which the fuzzy approaches could be directly applied to or because their benefits are not appreciated.

- New fuzzy approaches focused in new trends for recommender systems. It is necessary to apply fuzzy to solving emerging problems such as group recommendation, context-aware recommendation or natural noise management, for improving the management of the uncertainty associated to such problems.

- New fuzzy approaches focused on using emergent information sources. In this way, although this survey has shown that there have been developed some works that consider the fuzzysupported uncertain information management in emergent sources such as social networks information, tagging systems or complex items (e.g. tree-structured items), further works are necessary in this direction. Overall, it is necessary proposals that could become starting-points for subsequent researches.

\section{Conclusions}

This survey analysed more than a hundred papers focused on the use of fuzzy techniques for supporting recommender systems. At first, these papers were arranged in three big groups according to three different recommendation paradigms (content-based, memory-based collaborative filtering, and modelbased collaborative filtering), additionally including several subgroups regarding the core computational approaches used in the corresponding works. Af- terwards, it was developed an exhaustive analysis of each contribution by considering, their key features, evaluation strategies, and application areas. Particularly, it includes a deeper analysis of the works identified as relevant inside its corresponding subgroup.

Eventually it has been pointed out future research avenues in fuzzy recommender systems, mainly focused on the development of a common framework, the development of evaluation scenarios centred on recommender systems based on fuzzy information management, and the development of new approaches for emergent information sources (e. g. social networks) and for solving new problems in recommender systems research (e. g. group recommendation, natural noise management).

We hope that this modest survey would be useful for the recommender systems research community, as a starting point for the development of further contributions to the emergent research field related to the development of recommender systems supported by fuzzy tools.

\section{Acknowledgements}

This research work was partially supported by the Research Project TIN2015-66524-P.

\section{References}

1. A. Abbas, L. Zhang, and S. U. Khan. A survey on context-aware recommender systems based on computational intelligence techniques. Computing, 97(7): 667-690, 2015.

2. M. N. M. Adnan, M. R. Chowdury, I. Taz, T. Ahmed, and R. M. Rahman. Content based news recommendation system based on fuzzy logic. In ICIEV, pages 1-6. IEEE, 2014.

3. G. Adomavicius and A. Tuzhilin. Toward the next generation of recommender systems: A survey of the state-of-the-art and possible extensions. IEEE Transactions on Knowledge and Data Engineering, 17(6): 734-749, 2005.

4. S. Aguzzoli, P. Avesani, and B. Gerla. A logical framework for fuzzy collaborative filtering. In $10 T H$ IEEE International Conference on Fuzzy Systems, pages 1043-1046. IEEE, 2001.

5. H. Al-Qaheri and S. Banerjee. Design and implementation of a policy recommender system towards social innovation: An experience with hybrid machine learn- 
ing. In Intelligent Data Analysis and Applications, pages 237-250. Springer, 2015.

6. M. Y. H. Al-Shamri and N. H. Al-Ashwal. Fuzzyweighted Pearson Correlation Coefficient for Collaborative Recommender Systems. In ICEIS, pages 409414,2013

7. M. Y. H. Al-Shamri and K. K. Bharadwaj. A compact user model for hybrid movie recommender system. In ICCIMA, pages 519-524, 2007.

8. M. Y. H. Al-Shamri and K. K. Bharadwaj. Fuzzygenetic approach to recommender systems based on a novel hybrid user model. Expert Systems with Applications, 35(3):1386-1399, 2008.

9. D. Anand and B. S. Mampilli. Folksonomy-based fuzzy user profiling for improved recommendations. Expert Systems with Applications, 41(5):2424-2436, 2014.

10. S. Ashkezari-T and M.-R. Akbarzadeh-T. FuzzyBayesian Network Approach to Genre-based Recommender Systems. In FUZZ-IEEE 2010, 2010.

11. T. Bai, B. Ding, Y. Wang, J. Ning, and L. Huang. A collaborative filtering algorithm based on citation information. In Logistics Engineering, Management and Computer Science, 2015 International Conference on, pages 952-956. Atlantis-Press, 2015.

12. M. Balabanović and Y. Shoham. Fab: content-based, collaborative recommendation. Communications of the ACM, 40(3):66-72, 1997.

13. L. Banda and K. Bharadwaj. An approach to enhance the quality of recommendation using collaborative tagging. International Journal of Computational Intelligence Systems, 7(4):650-659, 2014.

14. P. Bedi and S. K. Agarwal. A situation-aware proactive recommender system. In HIS, pages 85-89. IEEE, 2012.

15. P. Bedi and P. Vashisth. Empowering recommender systems using trust and argumentation. Information Sciences, 279:569-586, 2014.

16. J. C. Bezdek, R. Ehrlich, and W. Full. Fcm: The fuzzy c-means clustering algorithm. Computers \& Geosciences, 10(2-3):191-203, 1984.

17. K. K. Bharadwaj and M. Y. H. Al-Shamri. Fuzzy computational models for trust and reputation systems. Electronic Commerce Research and Applications, 8 (1):37-47, 2009.

18. A. Bilge and H. Polat. A comparison of clustering-based privacy-preserving collaborative filtering schemes. Applied Soft Computing, 13(5):24782489, 2013.

19. C. Birtolo and D. Ronca. Advances in Clustering Collaborative Filtering by means of Fuzzy C-means and trust. Expert Systems with Applications, 40(17):69977009, 2013.

20. J. Bobadilla, F. Ortega, and A. Hernando. A collaborative filtering similarity measure based on singular- ities. Information Processing \& Management, 48(2): 204-217, 2012.

21. J. Bobadilla, F. Ortega, A. Hernando, and A. Gutiérrez. Recommender systems survey. Knowledge-Based Systems, 46(0):109 - 132, 2013. ISSN 0950-7051.

22. R. Burke. Hybrid recommender systems: Survey and experiments. User modeling and user-adapted interaction, 12(4):331-370, 2002.

23. P. G. Campos, F. Díez, and I. Cantador. Time-aware recommender systems: a comprehensive survey and analysis of existing evaluation protocols. User Modeling and User-Adapted Interaction, 24(1-2):67-119, 2014.

24. E. J. Castellano, L. Martínez, and P. J. Sánchez. Orieb, a linguistic crs for supporting decision making in academic orientation. In FLINS, volume 21, page 24. World Scientific, 2008.

25. J. Castro, R. Yera Toledo, and L. Martínez. An empirical study of natural noise management in group recommendation systems. Decision Support Systems, 94: 1-11, 2017.

26. J. Castro, F. J. Quesada, I. Palomares, and L. Martínez. A Consensus-Driven Group Recommender System. International Journal of Intelligent Systems, 30(8): 887-906, 2015.

27. R.-M. Chao, J.-T. Huang, and C.-W. Yang. The study of knowledge service-oriented recommendation mechanism-a case of e-learning platform. In ICMLC, volume 4, pages 2228-2233. IEEE, 2005.

28. C. Chen and W. Tai. A user preference classification method in information recommendation system. In ICEB, pages 1091-1096, 2004.

29. D. Chen, Y. Ying, and S. Gong. A collaborative filtering algorithm based on rough set and fuzzy clustering. In FSKD, volume 1, pages 17-20. IEEE, 2008.

30. L.-C. Cheng and H.-A. Wang. A fuzzy recommender system based on the integration of subjective preferences and objective information. Applied Soft Computing, 18:290-301, 2014.

31. C. Christakou, S. Vrettos, and A. Stafylopatis. A hybrid movie recommender system based on neural networks. International Journal on Artificial Intelligence Tools, 16(5):771-792, 2007.

32. C. Cornelis, J. Lu, X. Guo, and G. Zhang. Oneand-only item recommendation with fuzzy logic techniques. Information Sciences, 177(22):4906-4921, 2007.

33. L. M. de Campos, J. M. Fernandez-Luna, and J. F. Huete. A collaborative recommender system based on probabilistic inference from fuzzy observations. Fuzzy Sets and Systems, 159(12):1554-1576, 2008.

34. M. de Gemmis, P. Lops, C. Musto, F. Narducci, and G. Semeraro. Semantics-aware content-based recommender systems. In Recommender Systems Hand- 
book, pages 119-159. Springer US, 2015.

35. M. K. K. Devi and P. Venkatesh. Smoothing approach to alleviate the meager rating problem in collaborative recommender systems. Future Generation Computer Systems, 29(1):262-270, 2013.

36. Y. Djaghloul, V. Groues, and Y. Naudet. Combining situation and content similarities in fuzzy based interest matchmaking mechanism. In SMAP, pages 9-14. IEEE, 2012.

37. M. D. Ekstrand, J. T. Riedl, and J. A. Konstan. Collaborative filtering recommender systems. Foundations and Trends in Human-Computer Interaction, 4(2):81173, 2011.

38. M. H. Esfahani and F. K. Alhan. New hybrid recommendation system based on c-means clustering method. In IKT, pages 145-149. IEEE, 2013.

39. P. Fang and S. Zheng. A research on fuzzy formal concept analysis based collaborative filtering recommendation system. In $K A M$, volume 3, pages 352-355. IEEE, 2009.

40. G. Fenza, E. Fischetti, D. Furno, and V. Loia. A hybrid context aware system for tourist guidance based on collaborative filtering. In FUZZ-IEEE, pages 131138, 2011.

41. M. Gao, K. Liu, and Z. Wu. Personalisation in web computing and informatics: Theories, techniques, applications, and future research. Information Systems Frontiers, 12(5):607-629, 2010.

42. V. C. Gerogiannis, A. Karageorgos, L. Liu, and C. Tjortjis. Personalised fuzzy recommendation for high involvement products. In IEEE SMC, pages 4884-4890. IEEE, 2013.

43. C. Guan, K. K. F. Yuen, and F. Coenen. Towards an intuitionistic fuzzy agglomerative hierarchical clustering algorithm for music recommendation in folksonomy. In IEEE SMC, pages 2039-2042. IEEE, 2015.

44. A. Gunawardana and G. Shani. A survey of accuracy evaluation metrics of recommendation tasks. Journal of Machine Learning Research, 10:2935-2962, 2009.

45. H. Q. He and Z. L. Fan. An Improved Collaborative Filtering Recommendation Algorithm Based on Coclustering. In AETIE, pages 508-515, 2015.

46. F. Herrera and L. Martínez. A 2-tuple fuzzy linguistic representation model for computing with words. IEEE Transactions on fuzzy systems, 8(6):746-752, 2000.

47. J. H. Holland. Adaptation in natural and artificial systems: an introductory analysis with applications to biology, control, and artificial intelligence. U Michigan Press, 1975.

48. K. Honda, I. Hidetomo, and A. Notsu. A sequential learning algorithm for collaborative filtering with linear fuzzy clustering. In IEEE SMC, volume 2, pages 1056-1061. IEEE, 2006.

49. K. Honda, A. Notsu, and H. Ichihashi. Collaborative filtering by sequential extraction of user-item clusters based on structural balancing approach. In FUZZIEEE, pages 1540-1545. IEEE, 2009.

50. T. Horváth. A model of user preference learning for content-based recommender systems. Computing and informatics, 28(4):453-481, 2009.

51. Y.-C. Hu. Nonadditive similarity-based single-layer perceptron for multi-criteria collaborative filtering. Neurocomputing, 129:306-314, 2014.

52. Y.-C. Hu, Y.-J. Chiu, Y.-L. Liao, and Q. Li. A fuzzy similarity measure for collaborative filtering using nonadditive grey relational analysis. Journal of Grey System, 27(2), 2015.

53. H.-H. Huang, H.-C. Yang, and E. H.-C. Lu. A FuzzyRough Set based Ontology for Hybrid Recommendation. In ICCE-TW, pages 358-359, 2015.

54. J.-S. Jang. Anfis: adaptive-network-based fuzzy inference system. IEEE transactions on Systems, Man, and Cybernetics, 23(3):665-685, 1993.

55. T. Jeon, J. Cho, S. Lee, G. Baek, and S. Kim. A movie rating prediction system of user propensity analysis based on collaborative filtering and fuzzy system. In FUZZ-IEEE, pages 507-511. IEEE, 2009.

56. A. Jøsang and R. Ismail. The beta reputation system. In Proceedings of the 15th bled electronic commerce conference, volume 5, pages 2502-2511, 2002.

57. V. Kant and K. K. Bharadwaj. Enhancing Recommendation Quality of Content-based Filtering through Collaborative Predictions and Fuzzy Similarity Measures. In ICMOC, pages 939-944, 2012.

58. V. Kant and K. K. Bharadwaj. Fuzzy Computational Models of Trust and Distrust for Enhanced Recommendations. International Journal of Intelligent Systems, 28(4):332-365, 2013.

59. V. Kant and K. K. Bharadwaj. Integrating collaborative and reclusive methods for effective recommendations: a fuzzy bayesian approach. International Journal of Intelligent Systems, 28(11):1099-1123, 2013.

60. N. Karacapilidis and L. Hatzieleftheriou. Exploiting similarity measures in multi-criteria based recommendations. In $E C$-WEB, pages 424-434, 2003.

61. R. Katarya and O. P. Verma. A collaborative recommender system enhanced with particle swarm optimization technique. Multimedia Tools and Applications, pages 1-15, 2016.

62. W. Kim, I.-J. Ko, J.-S. Yoon, and G.-Y. Kim. Inference of recommendation information on the internet using improved fam. Future Generation Computer Systems, 20(2):265-273, 2004.

63. A. Klašnja-Milićević, M. Ivanović, and A. Nanopoulos. Recommender systems in e-learning environments: a survey of the state-of-the-art and possible extensions. Artificial Intelligence Review, 44(4):571604, 2015.

64. M. Komkhao, J. Lu, Z. Li, and W. A. Halang. Incremental collaborative filtering based on Mahalanobis 
distance and fuzzy membership for recommender systems. International Journal of General Systems, $\mathbf{4 2}$ (1):41-66, 2013.

65. J. A. Konstan and J. Riedl. Recommender systems: from algorithms to user experience. User Modeling and User-Adapted Interaction, 22(1-2):101-123, 2012.

66. H. Koohi and K. Kiani. User based Collaborative Filtering using fuzzy C-means. Measurement, 91:134139, 2016.

67. P. Ladyzynski and P. Grzegorzewski. Vague preferences in recommender systems. Expert Systems with Applications, 42(24):9402-9411, 2015.

68. Y. LeCun, Y. Bengio, and G. Hinton. Deep learning. Nature, 521:436-444, 2015.

69. S. Lee. Personal recommendation based on a user's understanding. Computer Applications in Engineering Education, 20(1):62-71, 2012.

70. C. W.-k. Leung, S. C.-f. Chan, and F.-l. Chung. A collaborative filtering framework based on fuzzy association rules and multiple-level similarity. Knowledge and Information Systems, 10(3):357-381, 2006.

71. J.-h. Li, X.-s. Li, H.-1. Liu, X.-j. Han, and J. Zhang. Fuzzy collaborative filtering approach based on semantic distance. In Fuzzy Information and Engineering Volume 2, pages 187-195. Springer, 2009.

72. S. Linda and K. K. Bharadwaj. A fuzzy trust enhanced collaborative filtering for effective context-aware recommender systems. In Proceedings of First International Conference on Information and Communication Technology for Intelligent Systems: Volume 2, pages 227-237. Springer, 2016.

73. H. Liu and Z. Yin. Applying multiple agents to fuzzy collaborative filtering. In 2009 International Conference on E-Business and Information System Security, pages 1-5. IEEE, 2009.

74. H. Liu, Z. Hu, A. Mian, H. Tian, and X. Zhu. A new user similarity model to improve the accuracy of collaborative filtering. Knowledge-Based Systems, 56: 156-166, 2014.

75. P. Lops, M. De Gemmis, and G. Semeraro. Contentbased recommender systems: State of the art and trends. In Recommender systems handbook, pages 73105. Springer, 2011.

76. J. Lu, D. Wu, M. Mao, W. Wang, and G. Zhang. Recommender system application developments: a survey. Decision Support Systems, 74:12-32, 2015.

77. J. Lu, Q. Shambour, Y. Xu, Q. Lin, and G. Zhang. A Web-Based Personalized Business Partner Recommendation System Using Fuzzy Semantic Techniques. Computational Intelligence, 29(1):37-69, 2013.

78. M. Mao, J. Lu, G. Zhang, and J. Zhang. A Fuzzy Content Matching-based e-Commerce Recommendation Approach. In FUZZ-IEEE), 2015.

79. L. Martínez, L. G. Pérez, and M. Barranco. A multigranular linguistic content-based recommendation model. International Journal of Intelligent Systems, 22(5):419-434, 2007.

80. L. Martínez, M. J. Barranco, L. G. Perez, and M. Espinilla. A knowledge-based recommender system with multigranular linguistic information. International Journal of Computational Intelligence Systems, 1(3):225-236, 2008.

81. L. Martínez, D. Ruan, and F. Herrera. Computing with words in decision support systems: an overview on models and applications. International Journal of Computational Intelligence Systems, 3(4):382-395, 2010.

82. L. Martínez, F. Herrera, et al. An overview on the 2-tuple linguistic model for computing with words in decision making: Extensions, applications and challenges. Information Sciences, 207:1-18, 2012.

83. L. Martínez, J. Castro, and R. Yera. Managing natural noise in recommender systems. In TPNC, pages 3-17. Springer, 2016.

84. L. Martínez, L. G. Perez, M. Barranco, and M. Espinilla. Improving the effectiveness of knowledge based recommender systems using incomplete linguistic preference relations. International Journal of Uncertainty Fuzziness and Knowledge-Based Systems, 16(2):33-56, 2008.

85. M. B. Menhaj and S. Jamalzehi. Scalable user similarity estimation based on fuzzy proximity for enhancing accuracy of collaborative filtering recommendation. In ICCIA, pages 220-225. IEEE, 2016.

86. S. Min and I. Han. Dynamic fuzzy clustering for recommender systems. In PAKDD, pages 480-485, 2005.

87. N. Mittal, M. Govil, R. Nayak, G. R, and D. Das. A hybrid clustering based filtering approach with efficient sequencing. In Proceedings of the International MultiConference of Engineers and Computer Scientists, volume 1. IAENG, 2008.

88. J. M. Morales-del Castillo, E. Peis, J. M. Moreno, and E. Herrera-Viedma. D-fussion: A semantic selective disssemination of information service for the research community in digital libraries. Information Research: An International Electronic Journal, 14(2), 2009.

89. C. Musto, G. Semeraro, P. Lops, M. de Gemmis, and G. Lekkas. Personalized finance advisory through case-based recommender systems and diversification strategies. Decision Support Systems, 77:100-111, 2015.

90. D. A. Nguyen and T. H. Duong. Video recommendation using neuro-fuzzy on social tv environment. In Advanced Computational Methods for Knowledge Engineering, pages 291-298. Springer, 2015.

91. M. Nilashi, O. bin Ibrahim, and N. Ithnin. Multicriteria collaborative filtering with high accuracy using higher order singular value decomposition and neuro-fuzzy system. Knowledge-Based Systems, 60: 
82-101, 2014.

92. M. Nilashi, O. bin Ibrahim, N. Ithnin, and N. H. Sarmin. A multi-criteria collaborative filtering recommender system for the tourism domain using expectation maximization (em) and pca-anfis. Electronic Commerce Research and Applications, 14(6): 542-562, 2015.

93. M. Nilashi, O. bin Ibrahim, and N. Ithnin. Hybrid recommendation approaches for multi-criteria collaborative filtering. Expert Systems with Applications, 41(8): 3879-3900, 2014.

94. X. Ning, C. Desrosiers, and G. Karypis. A comprehensive survey of neighborhood-based recommendation methods. In Recommender Systems Handbook, pages 37-76. Springer US, 2015.

95. J. M. Noguera, M. J. Barranco, R. J. Segura, and L. Martínez. A mobile 3D-GIS hybrid recommender system for tourism. Information Sciences, 215:37-52, 2012.

96. I. Pardines, V. López, A. Sanmartín, M. O. de Toledo, and C. Fernández. Collaborative recommendation system for environmental activities management mobile application. In ISKE, pages 327-335. Springer, 2014.

97. M. J. Pazzani. A framework for collaborative, contentbased and demographic filtering. Artificial Intelligence Review, 13(5-6):393-408, 1999.

98. J. Pinho Lucas, A. Laurent, M. N. Moreno, and M. Teisseire. A fuzzy associative classification approach for recommender systems. International Journal of Uncertainty Fuzziness and Knowledge-Based Systems, 20(4):579-617, 2012.

99. M. A. Pinto, R. Tanscheit, and M. Vellasco. Hybrid recommendation system based on collaborative filtering and fuzzy numbers. In FUZZ-IEEE, pages 1-6. IEEE, 2012.

100. C. Porcel, A. Lṕpez-Herrera, and E. Herrera-Viedma. A recommender system to promoto collaborative research groups in an academic context. In FLINS, volume 21, page 24. World Scientific, 2008.

101. L. Qiao and R. Zhang. Personalized recommendation algorithm based on situation awareness. In LISS, pages 1-4. IEEE, 2015.

102. S. Queiroz, F. de Carvalho, G. Ramalho, and V. Corruble. Making recommendations for groups using collaborative filtering and fuzzy majority. In SBIA, pages 248-258, 2002.

103. M. Ramezani and F. Yaghmaee. A novel video recommendation system based on efficient retrieval of human actions. Physica A, 457:607-623, 2016.

104. J. A. Recio-García, B. Diaz-Agudo, S. GonzalezSanz, and L. Quijano Sanchez. Distributed Deliberative Recommender Systems. In Transactions on Computational Collective Intelligence I, pages 121-142, 2010.
105. M. Z. Reformat and R. R. Yager. Suggesting Recommendations Using Pythagorean Fuzzy Sets illustrated Using Netflix Movie Data. In Information Processing and Management of Uncertainty in Knowledge-Based Systems, PT I, pages 546-556, 2014.

106. P. Resnick, N. Iacovou, M. Suchak, P. Bergstrom, and J. Riedl. Grouplens: an open architecture for collaborative filtering of netnews. In $A C M C S C W$, pages 175-186, 1994.

107. R. M. Rodríguez and L. Martínez. An analysis of symbolic linguistic computing models in decision making. International Journal of General Systems, 42(1):121136, 2013.

108. R. M. Rodríguez, L. Martínez, and F. Herrera. Hesitant fuzzy linguistic term sets for decision making. IEEE Transactions on Fuzzy Systems, 20(1):109-119, 2012.

109. R. M. Rodríguez, M. Espinilla, P. J. Sanchez, and L. Martínez-Lopez. Using linguistic incomplete preference relations to cold start recommendations. Internet Research, 20(3):296-315, 2010.

110. R. M. Rodríguez, A. Labella, and L. Martínez. An Overview on Fuzzy Modelling of Complex Linguistic Preferences in Decision Making. International Journal of Computational Intelligence Systems, 9(1, SI): 81-94, 2016.

111. N. Sahoo, P. V. Singh, and T. Mukhopadhyay. A hidden markov model for collaborative filtering. MIS Quarterly, 36(4):1329-1356, 2012.

112. B. Sarwar, G. Karypis, J. Konstan, and J. Riedl. Itembased collaborative filtering recommendation algorithms. In $W W W$, pages 285-295. ACM, 2001.

113. J. B. Schafer, J. A. Konstan, and J. Riedl. Ecommerce recommendation applications. Data Mining and Knowledge Discovery, 5(1-2):115-153, 2001.

114. V. Schlecht and W. Gaul. Fuzzy two-mode clustering vs. collaborative filtering. In Classification - The Ubiquitous Challenge, pages 410-417, 2005.

115. J. Serrano-Guerrero, E. Herrera-Viedma, J. A. Olivas, A. Cerezo, and F. P. Romero. A google wave-based fuzzy recommender system to disseminate information in university digital libraries 2.0. Information $\mathrm{Sci}$ ences, 181(9):1503-1516, 2011.

116. J. Sobecki, E. Babiak, and M. Słanina. Application of hybrid recommendation in web-based cooking assistant. In KES, pages 797-804. Springer, 2006.

117. L. H. Son. HU-FCF: A hybrid user-based fuzzy collaborative filtering method in Recommender Systems. Expert Systems with Applications, 41(15):6861-6870, 2014.

118. L. H. Son and N. T. Thong. Intuitionistic fuzzy recommender systems: An effective tool for medical diagnosis. Knowledge-Based Systems, 74:133-150, 2015.

119. L. H. Son, N. T. H. Minh, K. M. Cuong, and N. V. Canh. An application of fuzzy geographically cluster- 
ing for solving the cold-start problem in recommender systems. In SoCPaR, pages 44-49. IEEE, 2013.

120. X. Su and T. M. Khoshgoftaar. A survey of collaborative filtering techniques. Advances in artificial intelligence, 2009:4, 2009.

121. B. Suryavanshi, N. Shiri, and S. Mudur. Improving the effectiveness of model based recommender systems for highly sparse and noisy web usage data. In WI, pages 618-621, 2005.

122. Y. Teng, L. Zhang, Y. Tian, and X. Li. A novel fahp based book recommendation method by fusing apriori rule mining. In ISKE, pages 237-243. IEEE, 2015.

123. N. T. Thong and L. H. Son. HIFCF: An effective hybrid model between picture fuzzy clustering and intuitionistic fuzzy recommender systems for medical diagnosis. Expert Systems with Applications, 42(7): 3682-3701, 2015.

124. S. Tiwari and S. Kaushik. Crowdsourcing Based Fuzzy Information Enrichment of Tourist Spot Recommender Systems. In ICCSA, pages 559-574, 2015.

125. K. Treerattanapitak and C. Jaruskulchai. Exponential fuzzy c-means for collaborative filtering. Journal of Computer Science and Technology, 27(3):567-576, 2012.

126. C.-H. Tsai. A fuzzy-based personalized recommender system for local businesses. In ACM HT, pages 297302. ACM, 2016.

127. S. Tyagi and K. K. Bharadwaj. Trust-enhanced recommender system based on case-based reasoning and collaborative filtering. In ICPCES, pages 1-4. IEEE, 2012.

128. B. Veloso, B. Malheiro, and J. C. Burguillo. A multiagent brokerage platform for media content recommendation. International Journal of Applied Mathematics and Computer Science, 25(3):513-527, 2015.

129. S. K. Verma, N. Mittal, and B. Agarwal. Hybrid Recommender System based on Fuzzy Clustering and Collaborative Filtering. In ICCCT, pages 116-120, 2013.

130. P. Victor, C. Cornelis, M. De Cock, and P. P. da Silva. Gradual trust and distrust in recommender systems. Fuzzy Sets and Systems, 160(10):1367-1382, 2009.

131. J. Vimali and Z. S. Taj. Fcm based cf: An efficient approach for consolidating big data applications. In International Conference on Innovation Information in Computing Technologies, pages 1-7. IEEE, 2015.

132. M. G. Vozalis and K. G. Margaritis. Using svd and demographic data for the enhancement of generalized collaborative filtering. Information Sciences, 177(15): 3017-3037, 2007.

133. R. Wang. Hybrid recommendation based on fuzzy clustering and data filling. In Information Computing And Automation: (In 3 Volumes), pages 59-63. World Scientific, 2008.

134. W. Wang, J. Lu, and G. Zhang. A New Similarity
Measure-Based Collaborative Filtering Approach for Recommender Systems. In ISKE, pages 443-452, 2014.

135. W.-J. Wang. New similarity measures on fuzzy sets and on elements. Fuzzy sets and systems, 85(3):305309, 1997.

136. M. Wasid and V. Kant. A Particle Swarm Approach to Collaborative Filtering based Recommender Systems through Fuzzy Features. In ICDMW, pages 440-448, 2015.

137. B. Widrow and M. A. Lehr. 30 years of adaptive neural networks: perceptron, madaline, and backpropagation. Proceedings of the IEEE, 78(9):1415-1442, 1990.

138. D. Wu, G. Zhang, and J. Lu. A fuzzy preference treebased recommender system for personalized businessto-business e-services. IEEE Transactions on Fuzzy Systems, 23(1):29-43, 2015.

139. D. Wu, J. Lu, and G. Zhang. A Fuzzy Tree MatchingBased Personalized E-Learning Recommender System. IEEE Transactions on Fuzzy Systems, 23(6): 2412-2426, 2015.

140. I. C. Wu and W.-H. Hwang. A genre-based fuzzy inference approach for effective filtering of movies. Intelligent Data Analysis, 17(6):1093-1113, 2013.

141. Z. Wu, Y. Chen, and T. Li. Personalized recommendation based on the improved similarity and fuzzy clustering. In ISEEE, volume 2, pages 1353-1357. IEEE, 2014.

142. Q. Xu, J. Wu, and Q. Chen. A novel mobile personalized recommended method based on money flow model for stock exchange. Mathematical Problems in Engineering, 2014, 2014.

143. S. Xu and J. Watada. A Method for Hybrid Personalized Recommender based on Clustering of Fuzzy User Profiles. In FUZZ-IEEE, pages 2171-2177, 2014.

144. R. Yager. On ordered weighted averaging aggregation operators in multicriteria decision making. IEEE Transactions on Systems, Man and Cybernetics, 18 (1):183-190, 1988.

145. R. Yager. Fuzzy logic methods in recommender systems. Fuzzy Sets and Systems, 136(2):133-149, 2003.

146. W.-S. Yang and Y.-R. Lin. A task-focused literature recommender system for digital libraries. Online Information Review, 37(4):581-601, 2013.

147. R. Yera Toledo and Y. Caballero Mota. An e-learning collaborative filtering approach to suggest problems to solve in programming online judges. International Journal of Distance Education Technologies, 12(2): 51-65, 2014

148. R. Yera Toledo, Y. Caballero Mota, and L. Martínez. Correcting noisy ratings in collaborative recommender systems. Knowledge-Based Systems, 76:96108, 2015.

149. R. Yera Toledo, J. Castro, and L. Martínez. A fuzzy 
model for managing natural noise in recommender systems. Applied Soft Computing, 40:187-198, 2016.

150. L. Zadeh. The concept of a linguistic variable and its applications to approximatereasoning. Part I. Information Sciencies, 8:199-249, 1975.

151. L. A. Zadeh. Fuzzy sets. Information and control, 8 (3):338-353, 1965.

152. A. Zenebe and A. F. Norcio. Representation, similarity measures and aggregation methods using fuzzy sets for content-based recommender systems. Fuzzy Sets and Systems, 160(1):76-94, 2009.

153. S. Zhang, C. Xi, Y. Wang, W. Zhang, and Y. Chen. A new method for e-government procurement using collaborative filtering and bayesian approach. The Scientific World Journal, 2013, 2013.

154. X. Zhang, W. Ma, and L. Chen. New similarity of triangular fuzzy number and its application. The Sci- entific World Journal, 2014, 2014.

155. Z. Zhang, H. Lin, K. Liu, D. Wu, G. Zhang, and J. Lu. A hybrid fuzzy-based personalized recommender system for telecom products/services. Information Sciences, 235:117-129, 2013.

156. W. X. Zhao, S. Li, Y. He, L. Wang, J.-R. Wen, and $\mathrm{X}$. Li. Exploring demographic information in social media for product recommendation. Knowledge and Information Systems, 49(1):61-89, 2015.

157. X. W. Zhao, Y. Guo, Y. He, H. Jiang, Y. Wu, and X. Li. We know what you want to buy: a demographic-based system for product recommendation on microblogs. In KDD, pages 1935-1944. ACM, 2014.

158. H.-J. Zimmermann. Fuzzy set theory and its applications. Springer Science \& Business Media, 2001. 